\title{
Effect of feeding calcium propionate on carcass composition, and productive performance of male broilers
}

Robert Eric Jones

West Virginia University

Follow this and additional works at: https://researchrepository.wvu.edu/etd

\section{Recommended Citation}

Jones, Robert Eric, "Effect of feeding calcium propionate on carcass composition, and productive performance of male broilers" (1999). Graduate Theses, Dissertations, and Problem Reports. 978. https://researchrepository.wvu.edu/etd/978

This Thesis is protected by copyright and/or related rights. It has been brought to you by the The Research Repository @ WVU with permission from the rights-holder(s). You are free to use this Thesis in any way that is permitted by the copyright and related rights legislation that applies to your use. For other uses you must obtain permission from the rights-holder(s) directly, unless additional rights are indicated by a Creative Commons license in the record and/ or on the work itself. This Thesis has been accepted for inclusion in WVU Graduate Theses, Dissertations, and Problem Reports collection by an authorized administrator of The Research Repository @ WVU. For more information, please contact researchrepository@mail.wvu.edu. 


\title{
EFFECT OF FEEDING CALCIUM PROPIONATE ON CARCASS COMPOSITION, AND PRODUCTIVE PERFORMANCE OF MALE BROILERS
}

ROBERT ERIC JONES, B.S. AN.\& VET. SCI .

THESIS SUBMITTED TO THE

COLLEGE OF AGRICULTURE, FORESTRY AND CONSUMER SCIENCES AT WEST VIRGINIA UNIVERSITY IN PARTIAL FULFILLMENT OF THE REQUIREMENTS FOR THE DEGREE OF

\author{
MASTER OF SCIENCE \\ IN \\ ANIMAL AND VETERINARY SCIENCES \\ RONALD A. PETERSON, Ph.D., CHAIR \\ HILLAR KLANDORF, $\mathrm{Ph} . \mathrm{D}$. \\ EDWARD C. PRIGGE, Ph.D. \\ DEPARTMENT OF ANIMAL AND VETERINARY SCIENCES \\ MORGANTOWN, WEST VIRGINIA \\ 1999
}

KEYWORDS: CALCIUM PROPIONATE, CARCASS COMPOSITION, PLASMA GLUCOSE, GROWTH HORMONE 


\section{Effect of Feeding Calcium Propionate on Carcass Composition and productive Performance of Male Broilers \\ Robert Eric Jones}

\section{(ABSTRACT)}

Male broilers were fed ad libitum a control diet and diets with $1.5 \%$ and $2.7 \%$ calcium propionate (CaP). Broiler diets were supplemented with CaP for the first 2,4,6, or 8week intervals. After being fed CaP for the previous mentioned times the broilers received a control diet for the remainder of each period. All broilers supplemented with CaP had lower body weights $(p>.01)$. Fat pad weight was lower in CaP treated broilers slaughtered at 8 weeks of age (p>.01). Percent carcass fat was lower in CaP treated birds ( $p>.01)$. Percent carcass fat was lower in CaP treated birds (p>.01). Percent carcass protein was higher in CaP treated birds (p>.01). Plasma glucose level was increased in CaP broilers at 4,6 , and 8 weeks, whereas growth hormone levels were increased in CaP broilers at 6 and 8 weeks. In, summary the inclusion of $\mathrm{CaP}$ in the diet of broilers lowered body weights, carcass composition and increases levels of plasma glucose and growth hormone.

Key words: Calcium Propionate, Carcass Composition, Plasma Glucose, Growth Hormone 


\section{ACKNOWLEDGMENTS}

The author wishes to express his sincere thanks and appreciation to my committee members: Dr. Ronald A. Peterson, Dr. Hillar Klandorf, and Dr. Edward C. Prigge for their advice and guidance in the preparation and organization of this thesis. They provided valuable insight and help in the completion of this research project. Dr. Peterson was very supportive and was always there to listen to questions that arose during the process. Dr. Klandorf provided his vast knowledge of plasma glucose and growth hormone levels as well as his writing skills to assist me in completing this project. Dr. Prigge provided his nutritional knowledge and insights to make the project come together. I would also like to thank Dr. Townsend for his guidance in interpreting the statistical data. During the research trials the poultry farm crew provided assistance in the care taking and data measurements throughout the project, for that assistance I am grateful.

My father provided continued long distance support and helped serve as a conduit to the University providing the committee with my updated work as I matriculated at Rocco in Harrisonburg, Virginia. My father's persistence and Dr. Peterson and Dr. Klandorf's belief in the research provided me with the support to complete my project.

Last but not least, I wish to thank my family for their continuous and unwavering support in seeing my goal come to its fruition. My wife, Siobhan provided me her love, encouragement and assistance in making this research presentable. My parents, who not only provided me with an environment to attain knowledge, but the life skills and moral character necessary, to make this lifetime goal become a reality. 


\title{
TABLE OF CONTENTS
}

\author{
ABSTRACT \\ $\begin{array}{ll}\text { ACKNOWLEDGEMENTS } & \text { III }\end{array}$ \\ LIST OF FIGURES $\quad$ V \\ $\begin{array}{ll}\text { LIST OF APPENDIX } & \text { VII }\end{array}$ \\ INTRODUCTION \\ REVIEW OF LITERATURE \\ Feed Restriction 2 \\ Calcium Propionate 9 \\ Carcass composition 11 \\ Objectives 13 \\ $\begin{array}{ll}\text { MATERIALS AND METHODS } & 14\end{array}$ \\ $\begin{array}{ll}\text { RESULTS } & 20 \\ \text { Body Weight } & 20\end{array}$ \\ $\begin{array}{ll}\text { Weight Gain } & 26\end{array}$ \\ Carcass Fat, Fat Pad Weights and Carcass Protein 33 \\ Live and Dressed Carcass Weight 38 \\ Plasma Growth Hormone and Glucose 41 \\ DISCUSSION \\ $\begin{array}{ll}\text { CONCLUSION } & 56\end{array}$ \\ LITERATURE CITED \\ $\begin{array}{lll}\text { APPENDIX } & 1 . & 63\end{array}$ \\ $\begin{array}{lr}\text { VITA } & 69\end{array}$ \\ $\begin{array}{ll}\text { APPROVAL OF EXAMINING COMMITTEE } & 70\end{array}$
}


Average weight of broilers fed calcium propionate 2 weeks and finished on control feed for 6 weeks.....

Average weight of broilers fed calcium propionate 4 weeks and finished on control feed for 4 weeks.....

Average weight of broilers fed calcium propionate 6 weeks and finished on control feed for 2 weeks.........

Average weight of broilers fed calcium propionate 8 weeks.

Weight gain of broilers fed calcium propionate for 2 weeks and finished on control feed for 6 weeks.........

Weight gain of broilers fed calcium propionate for 4 weeks and finished on control feed for 4 weeks.........

Weight gain of broilers fed calcium propionate for 6 weeks and finished on control feed for 2 weeks.........

Weight gain of broilers fed calcium propionate for 8 weeks.

Average 8 week feed to gain ratio of broilers fed calcium propionate at $1.5 \%$ and $2.7 \%$ and finished on control feed.

Percent carcass fat of eviscerated 8 week old broilers fed calcium propionate at $1.5 \%$ and $2.7 \%$ and finished on control feed.

Fat pad weight of eviscerated 8 week old broilers fed calcium propionate at $1.5 \%$ and $2.7 \%$ and finished on control feed.

Percent protein of eviscerated 8 week old broilers fed calcium propionate at $1.5 \%$ and $2.7 \%$ and finished on control feed.

Live weight of 8 week old broilers......................................................... 39

Carcass weight of 8 week old broilers.............................................. 40

Plasma growth hormone level of broilers fed calcium propionate for 2 weeks and finished on control feed for 6 weeks.. 


\section{List of Figures}

Figure

Page

16 Plasma growth hormone level of broilers fed calcium propionate for weeks and finished on control feed for 4 weeks.....................................................................................................................................

17 Plasma growth hormone level of broilers fed calcium propionate for 6 weeks finished on control feed for 2 weeks.

18 Plasma growth hormone level of broilers fed calcium propionate for 8 weeks............................................................................................ 46

19 Plasma glucose level of broilers fed calcium propionate for 2 weeks and finished on control feed for 6 weeks...... 47

20 Plasma glucose level of broilers fed calcium propionate for 4 weeks and finished on control feed for 4 weeks.........48

21 Plasma glucose level of broilers fed calcium propionate for 6 weeks and finished on control feed for 2 weeks.........49

Plasma glucose level of broilers fed calcium propionate for 8 weeks 


\section{List of Appendix Tables}

Table

1

2

3

4

5

6
Average Weight of Broilers Fed Calcium Propionate For 2 Weeks and Finished On Control Feed For 6 Weeks

Average Weight of Broilers Fed Calcium Propionate For 4 Weeks and Finished On Control Feed For 4

Weeks

Average Weight of Broilers Fed Calcium Propionate For 6 Weeks and Finished On Control Feed For 2

Weeks

Average Weight of Broilers Fed Calcium Propionate For 8 Weeks.

Weight Gain of Broilers Fed Calcium Propionate For 2 Weeks and Finished On Control Feed For 6 Weeks......

Weight Gain of Broilers Fed Calcium Propionate For 4 Weeks and Finished On Control Feed For 4 Weeks......

Weight Gain of Broilers Fed Calcium Propionate For 6 Weeks and Finished On Control Feed For 2 Weeks......

Weight Gain of Broilers Fed Calcium Propionate For

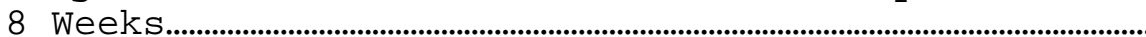

Average 8 Week Feed to Gain Ratio of Broilers Fed Calcium Propionate at $1.5 \%$ and $2.7 \%$ and Finished On Control Feed.

Percent Carcass Fat of Eviscerated 8 Week Old Broilers Fed Calcium Propionate at $1.5 \%$ and $2.7 \%$ and Finished On Control Feed.

Fat Pad Weight of Eviscerated 8 Week Old Broilers Fed Calcium Propionate at $1.5 \%$ and $2.7 \%$ and Finished On Control Feed.

Percent Protein of Eviscerated 8 Week Old Broilers Fed Calcium Propionate at $1.5 \%$ and $2.7 \%$ and Finished On Control Feed.

Live Weight of 8 Week Old Broilers.

66 
15 Plasma Growth Hormone Level of Broilers Fed Calcium Propionate For 2 Weeks and Finished On Control Feed for 6 Weeks.

Plasma Growth Hormone Level of Broilers Fed Calcium Propionate For 4 Weeks and Finished On Control Feed for 4 Weeks..

17 Plasma Growth Hormone Level of Broilers Fed Calcium Propionate For 6 Weeks and Finished On Control Feed for 2 Weeks.

18 Plasma Growth Hormone Level of Broilers Fed Calcium Propionate For 8 Weeks.

Plasma Glucose Level of Broilers Fed Calcium Propionate For 2 Weeks and Finished On Control Feed For 6 Weeks.

Plasma Glucose Level of Broilers Fed Calcium Propionate For 4 Weeks and Finished On Control Feed For 4 Weeks

Plasma Glucose Level of Broilers Fed Calcium Propionate For 6 Weeks and Finished On Control Feed

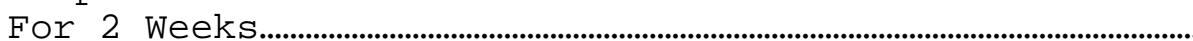




\section{Chapter 1. Introduction}

In broilers, restriction of feed intake improves feed efficiency and reduces deposition of body fat (Beane et al., 1979, Mollison et al., 1984; Plavnik and Hurwitz, 1985; Plavnik et al., 1986). Standard industry practices restrict feed intake by physical means and allot a fixed amount of feed at established intervals. However, it was Fancher and Jensen (1988) who first demonstrated an alternative, chemical method of feed restriction.

They demonstrated that the inclusion of glycolic acid in the diet of the broiler chick depressed feed intake in a dose-dependent manner. Comparable diets supplemented with calcium propionate (propionic acid) also reduce feed intake and body weights of broilers up to 10 weeks of age (Cave, 1984 and Pinchasov, 1993). However, it has not been determined whether chemically restricted chicks can regain the lost weight upon removal of the anorectic agent from the diet and if so, in what fat/protein ratio the compensatory gain is manifested. 


\section{Chapter 2. Review of Literature}

\subsection{Feed Restriction}

In response to genetic selection and improved nutrition, the body weights of 8 week old broiler chickens has increased by an average of $40 \mathrm{~g} / \mathrm{yr}$. over the past 30 years (Mallard and Douaire, 1988). The most dramatic increase in growth occurs in the first four weeks post hatch. However, excessive fat accumulation and an increased incidence of skeletal and metabolic diseases often accompany this early rapid growth phase.

Most studies investigating the effects of early feed restriction have dealt with feed efficiency and body fat accumulation. Pasternak and Shalev (1983) suggested that broilers exhibiting a concave-shaped growth curve (slow growth phase initially followed by a rapid growth phase) require less feed than broilers exhibiting a convex-shaped growth curve (growing fast initially and slower later). Commercial broilers exhibit a convex-shaped growth curve (Marks, 1979). Plavnik and Hurwitz (1985) demonstrated that in broilers feed restriction in the second week post hatch produces a concave-shaped growth curve, resulting in improved feed efficiency, a leaner bird and no reduction in body weight at eight weeks of age. In contrast, numerous researchers (Robinson et al., 1992; Yu et al., 1990; 
Pinchasov et. al., 1985; Calvert et al., 1987) have not been able to demonstrate the broiler's ability to exhibit compensatory gain after a period of early feed restriction.

Compensatory growth (catch up growth) is defined as the rate of growth measured after a refeeding period in excess of that normally observed in the same breed of chicken at the same age (Yu et. al., 1990). The phenomenon of compensatory growth has been documented in animals (Wilson and Osbourn, 1960, and O'Donovan, 1984). In animal production, most studies of compensatory growth have been concerned with sheep and cattle with little information available on broiler chickens.

Normal growth of birds and mammals follows a predetermined growth curve although early feed restriction can dramatically alter growth pattern of the animal. When returned to ad libitum feeding conditions, accelerated growth occurs. The two current hypothesis put forward to explain the control mechanisms responsible for this accelerated growth are the "central control" hypothesis (Mosier, 1986) and the "peripheral control" hypothesis (Pitts, 1986, and Winick and Noble, 1966). The "central control" hypothesis suggests a set point for body size appropriate for each age and that this control is regulated by the central nervous system. In contrast, "peripheral control" hypothesis suggests that the regulation of body size reside in the tissues where cell 
number determines the extent of growth following a period of feed restriction.

Wilson and Osbourn (1960) observed that both the energy and nutrients, which support compensatory growth, originate from the reduced maintenance requirements associated with refeeding. Maintenance requirements of broilers include four components: basal metabolic rate (BMR), specific dynamic action, energy for activity, and energy for the maintenance of body temperature (Vohra et al., 1975). Graham and Searle (1975) suggested that during compensatory growth, the basal metabolic rate is lower than the predicted value for normal growth. They concluded that the energy required for compensatory growth is obtained by the increased food intake relative to body size.

During a period of restriction, chickens can be fed at, above, or below maintenance energy requirements. The more severe the restriction, the greater is the initial catch up growth upon refeeding. The accumulation of body fat associated with refeeding after fasting (Yeh and Leveille, 1970) or the possibility of permanently stunting the animal (Barnes and Miller, 1981) has discouraged the practice of feeding below maintenance levels.

The longer the duration of feed restriction, the more difficult it is for the animal to make up for the loss in body weight upon refeeding. In order to obtain complete catch up in 
growth, McMurtry et al., (1988) recommended restricting broiler males for no more than seven days and females no longer than five days .

Restricting feed intake of broilers in the final stages of production (5-8 weeks) allows little or no time for compensatory growth to occur. Robinson et al. (1992) showed that restricting feed intake of broilers from the second week post hatch for seven days significantly reduced skeletal problems associated with an early rapid growth phase.

Yu et al., (1990) found that broilers maintained at minimal growth for one week resumed growth upon refeeding with a curve similar to that of controls. Auckland (1972) observed that compensatory growth in turkeys often occurred late in the growth phase when the rate of body weight gain normally declined.

Male and female broilers differ in growth rate and body fat content (Fisher, 1984; Leenstra, 1986). Male and female broilers also differ in response to feed restriction (McMurtry, 1988). Plavnik and Hurwitz (1985) obtained complete catch up growth with male broilers, but they were unable to demonstrate catch up growth in female broilers. There is no information concerning the response of mixed-sex flocks to feed restriction. Different strains of chickens have different responses to feed restriction. Cherry et al. (1978) found that fast growing broilers exhibit 
little compensatory growth in comparison to relatively slower growing broilers.

Qualitative feed restriction (altering the composition of the ration by altering the energy or protein levels) is one method of restriction commonly employed. One way of doing this is by the use of low protein diets (Moran, 1979). According to National Research Council (1984) recommendations, broilers should receive 23\%, 20\%, and 18\% dietary protein during the starting, growing, and finishing period for optimal growth. When dietary protein is marginally deficient, broilers respond by increasing feed intake (Fisher, 1984). However, when dietary protein deficiency is severe, broilers respond by eating less (Plavnik and Hurwitz, 1990). Griffiths et al., (1977) lowered the energy of a broiler diet to $2233 \mathrm{kcal} \mathrm{ME} / \mathrm{kg}$ from $3087 \mathrm{kcal} \mathrm{ME} / \mathrm{kg}$ of feed by substituting ground yellow corn with oat meal as the chief ingredient. Chicks fed the low energy diet consumed significantly more feed than those fed the high energy diet. The chicks fed the low energy diet from zero to three weeks of age did not differ significantly in body weight or in abdominal fat pad development from the control birds at four weeks of age. Polin and Wolford (1973) observed that chickens could over-eat as much as $34.1 \%$ to compensate for diluted diets.

Quantitative feed restriction (altering the amount of feed 
available) is inconvenient due to the frequent weighing of feed needed to determine consumption. Adequate feeder space must be provided and the limited allotment of feed must be distributed evenly and quickly. Alternate forms of feed restriction have been proposed, including alteration of the photoperiod and the use of chemicals to suppress feed intake.

Altering the photoperiod for the specific purpose of restricting feed intake of broiler chickens has not been reported in the literature. Broilers exposed to continuous light will eat around-the-clock (Masic et al., 1974; Buyse and Decuypere, 1988). Commercial broiler chickens are normally exposed to continuous light or a 23 hours light: 1-hour dark regime. This lighting practice was based on experimental results which showed that broilers exposed to continuous light are superior in body weight gain to those exposed to other light / dark regimes (Beane et al., 1962; Moore, 1957). Despite the results of these early studies, the effect of various light periods on the growth rate of chickens is inconclusive. Classen and Riddell (1989) noticed that broiler chicks exposed to 6 hours light: 18 hours dark from three to 21 days of age ate significantly less feed compared to chicks exposed to 23 hours light: 1-hour dark. Reducing the light period to six hours in a twenty-four-hour day had no effect on overall feed conversion ratio and body weight. Chickens can learn to eat in 
the dark, but their feed intake in the dark is significantly reduced. Classen and Riddell (1989) also observed that chickens can learn to increase feed intake during the light period in anticipation of the dark period, but their intake is limited by their crop size.

The use of chemicals during the early period of growth may also depress the feed intake of broilers. Pinchasov and Jensen (1989) incorporated 1.5 and $3.0 \%$ glycolic acid into broiler starter feed and obtained 22\% and 50\% reduction, respectively, in feed intake of broilers from seven to 14 days of age. Lacy et al. (1982) significantly decreased feed consumption of broiler chickens with a pharmacological dosage of tryptophan (5 X normal daily intake). Tryptophan is the precursor of serotonin which has an inhibitory role in feeding behavior (Blundell, 1977). Cave (1984) supplemented broiler starter diets with varying levels of propionic acid and mixed it into the chick's drinking water to determine the effect on voluntary feed intake. At 28 days of age all birds receiving propionic acid at levels ranging from 1.0 to 10.0\% had significantly lower feed intakes and body weights as compared to the controls. Mortality increased as the level of propionic acid increased. Similarly, Pinchasov (1990) found that calcium propionate fed to broilers resulted in reduced feed intake and body weight. He observed that calcium propionate is most 
effective when fed at a level of $1.7 \%$. Pinchasov also reported that calcium propionate's effect declined as the broilers neared market age.

\section{$\underline{2.2}$ Calcium Propionate}

Inclusion of feed additives that have inhibitory effects on the appetite of chicks has been recently investigated. Using natural organic compounds present in animal tissues as feed additives is preferable to inorganic additives, in order to avoid tissue residue and other problems. Cave (1982) showed evidence that a few fatty acids, such as acetic and propionic, have a suppressive effect on the appetite of chicks. Cave (1984) reported that a broiler starter diet containing dietary propionic acid at levels up to $10 \%$ resulted in reduced feed intake and body weight gain in chicks during days zero to 28 .

Pinchasov and Jensen (1989) observed a significant linear depression in feed intake when the broiler starter diet was supplemented with 1.7 calcium propionate. The calcium salt (calcium propionate) had a greater depressive action than the free acid (propionic) in both weight gain and feed intakes. The inclusion of calcium propionate reduced abdominal fat in broilers at slaughter.

Broilers show compensatory growth during realimentation, following a period of restriction, or undernutrition (Plavnik and 
Hurwitz, 1991, and Zubair and Leeson, 1994). However, dietary restriction during the brooding period resulted in broilers that are lighter, due to either smaller body size, or less fat deposition at slaughter. Pinchasov (1993) observed that after 10 weeks of ad libitum feed consumption, calcium propionate supplementation proved less effective in controlling growth than conventional feed restriction regimes.

Pinchasov and Jensen (1989) reported that the depressive effect of propionate is not attributed to high acidity ( $\mathrm{pH}=2$ ) affecting acid-base balance, because the intubation of propionate neutralized by $\mathrm{KOH}$ caused a comparable depression of feed intake. It has been suggested that the administration of a high concentration of propionic acid resulted in a deficiency of vitamin B-12. Alternatively, high concentrations of propionic acid in the tissues may lead to the synthesis of increased levels of appetite-controlling factors such as the hypothalamic indoleamines.

Propionic acid-based mold inhibitors increase intestinal strength of poultry (Huff et al., 1994), through its role as a mold inhibitor and thus reducing the amount of mycotoxin released into the intestine. Huff (1994) suggested that a yet to be identified factor may be involved in proventriculitis (inflammation of the proventriculus), and this condition may be 
inhibited by propionic acid. However, Hume et al.,

observed that little propionic acid reaches the lower intestines, such that any effect of propionic acid would have to occur in the upper intestinal tract.

\subsection{Carcass Composition}

Wolynetz et al., (1986) conducted a study that predicted the yields of major body components of broiler chicks. The data was used to estimate total dry matter, energy, protein, fat, and ash content of broilers. Although carcass analysis is often avoided in many nutritional experiments because of the difficulty in preparing the necessary homogenates (Sibbald et al., 1982) Spencer et al., 1978, found high correlation between the total carcass fat of broilers and the abdominal fat pad. However, there are limitations in its accuracy, such as not providing researchers with energy, protein, dry matter, ash, and fat levels, that proximate analysis of the carcass provides. Proximate analysis also allows researchers to evaluate feed formulations and management procedures (Jurgens, 1988).

Feed restriction studies in broilers generally results in partial body weight compensation. Most studies reported improved feed efficiency and a reduction of body and abdominal fat, although final body weight was reduced. Beane et al., (1979) reported improved feed efficiency, but the size of the abdominal 
fat pad of male broilers was significantly increased by feed restriction and refeeding.

Protein level of the diet and frequency of feeding can significantly alter the body composition of broiler chickens. Studies have indicated that increasing the calorie to protein ratios in diets increases fat deposition, whereas decreasing the calorie to protein ratios decreased the fat content in broilers (Summers, et al., 1990; Bartov, 1987). Ballam and March (1979) noticed an increase in fat cell number and decrease in fat cell size in chickens limited to 30 minutes of feeding each day. Yu et al. (1990) compared the effect of different frequencies of feed intake during early feed restriction (8 to 14 days of age) on subsequent body composition. They observed that broiler chicks that were fed at hourly intervals during feed restriction had significantly less body fat at eight weeks of age than did chicks that were fed either once a day or every other day during the same period restriction.

The rapid increase in growth rate of modern broilers is associated with an increase in the incidence of leg problems and mortality. Robinson et al., (1992) demonstrated that severe feed restriction in the second week of growth significantly reduced the incidence of skeletal disease in broiler chickens. Robinson reported that the incidence of birds culled for skeletal disease 
was threefold higher in full-fed birds compared to birds that were feed restricted. A reduction in the incidence of leg disorders and sudden death syndrome was also observed in broilers exposed to intermittent, or a step-up lighting regimes (Buckland et al., 1976; Wilson et al., 1984). Wilson et al. (1984) reported that a decrease in leg abnormalities was due in part to an increase in the activity of broilers subjected to intermittent feeding. Cost benefits to industry are sustained when incidences of leg abnormalities and mortality are reduced.

\section{$\underline{2.4 \text { Objectives }}$}

The purpose of these studies was to determine the effects of feeding calcium propionate (propionic acid) on the productive performance (body weight, feed intake, feed efficiency), carcass composition, plasma concentrations of glucose, and plasma growth hormone concentrations of eight week old broilers. The studies also determined if compensatory growth could be achieved after chemical feed restriction. 


\section{Chapter 3. Materials and Methods}

\subsection{Experimental Procedure}

This experiment determined the effect of rations supplemented with 1.5 and 2.7\% calcium propionate. Male broiler chicks $(\mathrm{n}=1944)$ were randomly assigned to 36 pens with each pen containing 54 broilers. The experimental design and treatment design is as follows:

1.) 12 pens were fed control feed for the trial's eight week duration.

2.) 12 pens were randomly selected to receive a diet supplemented with 1.5\% CaP.

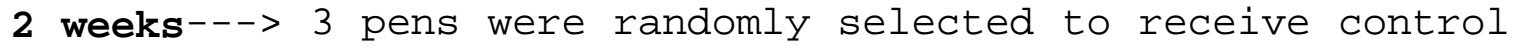
feed for the remainder of the trial.

4 weeks---> 3 pens were randomly selected to receive control feed for the remainder of the trial.

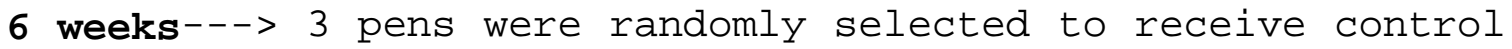
feed for the remainder of the trial.

The remaining 3 pens received $1.5 \% \mathrm{CaP}$ supplemented diet for the duration of the trial.

3.) 12 pens were randomly selected to receive a diet supplemented with 2.7\% CaP.

2 weeks---> 3 pens were randomly selected to receive control feed for the remainder of the trial. 
4 weeks w $^{-->} 3$ pens were randomly selected to receive control feed for the remainder of the trial.

6 weeks---> 3 pens were randomly selected to receive control feed for the remainder of the trial.

The remaining 3 pens received a 2.7\% CaP supplemented diet for the duration of the trial. The variables monitored at weeks four, six and eight included: carcass composition, productive performance (body weight and feed conversions), effect of calcium propionate, and brooding density.

At the onset of this experiment three birds from each of the 36 pens were randomly wing banded. Blood samples were obtained at weeks $0,2,4,6$, and 8 , in order to measure plasma glucose and growth hormone concentrations. Birds were weighed individually at weeks 2, 4, 6, and 8. Birds were processed at week 8, for measurement of fat pad weight, carcass as a percent live weight, fat, protein, moisture, and ash content.

Individual birds were weighed before and after total evisceration in order to calculate the carcass weight as a percentage of live weight. Eviscerated carcasses were sealed into vacuum bags and then frozen at $0^{\circ} \mathrm{F}$. Carcasses were removed from the bags and cut into cubes with a meat saw. The cubes were ground twice using a coarse and a fine die on a Biro grinder to a fine consistency. A fifty-gram sample was obtained from each 
ground sample, frozen in liquid nitrogen and then blended in a Waring blender until powdered. Approximately fifty-gram samples were placed into labeled Whirl-Pak bags and stored at $0 \circ \mathrm{F}$ until assayed. Carcass samples were prepared by taking random samples of ground-up carcass from each treatment.

Ether extract tests were run to determine the percent fat in each carcass. A Tecator Soxtec System HT 1043 Extraction Unit was used for the ether extract analysis. Approximately .500 $\mathrm{g}$ of a powdered sample was weighed-out into a tared cellulose thimble, placed into a metallic adapter, and covered with a thin layer of defatted cotton. Dried extraction cups containing 2-3 glassboiling chips were weighed and numbered according to the sample being tested. Forty $\mathrm{ml}$ of petroleum ether was added to each extraction cup. The cellulose thimbles were placed into the boiling chamber of the soxtec. The extraction cups were then inserted under the thimbles to collect the fat extracted from the carcass samples. The thimbles were then immersed into the extraction cups and boiled for 20 minutes. After boiling was completed, the thimbles were rinsed for 45 minutes. The condenser valves were closed in order to allow all the remaining solvent to be collected. After the solvent was collected, the extraction cups were removed from the soxtec system using the cup holder. The cups were dried in an oven set at 115-1200 C for 1-2 hours. 
The extraction cups were allowed to cool in a desiccator, and then weighed. The final weight of the cup and sample was used to determine the \% fat (grams of dry matter (DM) over the initial sample weight). Percent protein in the carcasses was determined by Kjeldahl analysis. A Tecator 1015 Digestion System and Kjeltec Auto 1030 Analyzer were used to run the protein percentage tests. Approximately .200 $\mathrm{g}$ of the freeze-dried carcass sample was weighed into Whatman No.1 $(7 \mathrm{~cm})$ filter paper formed into a boat. The weighed sample and tared filter paper were placed into digestion tubes along with one Kjel tab. Sulfuric acid (10 ml) was then added to each tube prior to placement on the tube warmers of the 1015 Digestion System for 45 minutes or until the samples turned green in color. Double distilled water $(75 \mathrm{ml}$ ) was added to each tube and any precipitate formed was swirled into solution. The digestion tubes were then assayed in duplicate on the 1030 Kjeltec Auto Analyzer. The amount of acid used to analyze the sample was recorded and used to determine the percent protein of each sample according to the formula: milliliters of acid titrated $\mathrm{x}$ acid normality $\mathrm{x} \mathrm{N}$ wt. $\mathrm{x}$ protein factor/1000/sample wt. $\mathrm{x} 100$.

Percent moisture was determined by weighing out approximately 2 grams of a powdered carcass sample into labeled and tared tin pans. The initial sample and pan weights were recorded. Placing in an oven at $100^{\circ} \mathrm{C}$ for 24 hours dried samples. The pans were 
cooled in a desiccator and then weighed. The pan weight and sample were subtracted from the initial pan weight in order to calculate the dry weight. The dry weight was divided by the initial sample weight and multiplied by 100 to get the percent dry weight. The percent moisture was calculated by subtracting the percent dry matter from 100 .

Percent ash was determined by weighing out approximately 2 grams of a powdered carcass sample into a labeled and tared crucible. The initial sample and crucible weights were recorded. The samples were placed in an ashing oven overnight at a temperature of $550^{\circ} \mathrm{F}$. The crucible and ashed sample weights were recorded after cooling in a desiccator. The dry weight was determined by subtracting the crucible and ash sample weights from the initial crucible weight. The o ash was calculated by dividing the dry weight by the initial sample weight and multiplying by 100 .

Plasma glucose levels were obtained by taking blood samples from the wing-banded birds at weeks 4,6, and 8. The blood was collected into Vacutainers and then centrifuged to separate the plasma. The plasma was drawn into labeled tubes and frozen until testing could be done. Plasma glucose was measured by a glucose oxidase method using a Beckman Analyzer.

Plasma growth hormone (GH) levels were determined by a 
radioimmunoassay (RIA). On day one frozen plasma samples were thawed by insertion into tepid water. Duplicate samples were aliquoted using a Digiflex at dilutions of $25 \lambda$ for week four samples and $100 \lambda$ for weeks six and eight. Primary antibody was added after 24 hours, the tubes were vortexed and refrigerated overnight at $4 \circ \mathrm{C}$. On day two, the tubes were placed into a water bath at $37^{\circ} \mathrm{C}$ for 24 hours. On day three, the second antibody was added. After incubation at $4^{\circ} \mathrm{C}$ overnight the tubes were centrifuged at $3500 \mathrm{rpm}$ and the precipitate counted in a gamma counter.

The data were analyzed by using the General Linear Models procedure of SAS software (SAS Institute, 1988). Significant differences between treatments were separated using Duncan's multiple range test (Duncan, 1955). Statements of statistical significance were based on $\mathrm{P}<.05$ unless otherwise noted. 


\section{Chapter 4. Results}

\subsection{Body Weight}

The average body weights of broilers fed diets supplemented with or without calcium propionate (CaP) are shown in figures 1-4. Each figure shows the effect of feeding CaP at both the $1.5 \%$ and 2. $7 \%$ level.

The effect of feeding CaP for the first 2 weeks after hatch and subsequently transferred to control feed for the remainder of the trial is presented in figure 1. The control treated group was significantly $(\mathrm{p}<.01)$ heavier than the broilers fed either the 1.5\% or $2.7 \%$ CaP diets at the end of the first two-week treatment period. At week 2, the broilers receiving the 1.5\% CaP diet were significantly $(p<.01)$ heavier than those fed at the $2.7 \%$ level. At weeks 4,6, and 8 there were no significant differences found between the control and $1.5 \%$ CaP diets. These two treatment levels were significantly $(\mathrm{p}<.01)$ heavier than the $2.7 \%$ treated broilers.

The CaP treated groups gained more weight (insert data) over the last 6 weeks when they were fed the control feed, but did not compensate to the weight measured in non-treated birds.

The effect of feeding broilers CaP diets for the first 4 weeks at the two aforementioned levels and then fed a control feed during the remainder of the trial is shown in figure 2. The control group was significantly $(\mathrm{p}<.01)$ heavier than the broilers 
fed either the $1.5 \%$ or $2.7 \% \mathrm{CaP}$ diets at the end of the four-week treatment period. The 1.5\% fed CaP group was also significantly $(\mathrm{p}<.01)$ heavier than the $2.7 \% \mathrm{CaP}$ fed group at week 4 . At 6 and 8 weeks the control and $1.5 \% \mathrm{CaP}$ fed groups were significantly $(\mathrm{p}<.01)$ heavier than the 2.7\% CaP fed groups. Although the 2.7\% CaP groups gained more weight over the last 4 weeks as compared to the control fed group, they were unable to completely compensate for treatment effects.

Figure 3 depicts the effect of feeding CaP to broilers for 6 weeks and transfer to control feed for 2 weeks. After 6 weeks the control group was significantly $(\mathrm{p}<.01)$ heavier in body weight than the $1.5 \%$ and $2.7 \% \mathrm{CaP}$ fed groups. At week 8 the 1.5\% $\mathrm{CaP}$ fed group and controls were significantly $(\mathrm{p}<.01)$ heavier than the 2.7\% CaP group. There were no significant differences between the control and 1.5\% CaP groups at this time.

The effect of feeding calcium propionate for 8 weeks is seen in figure 4. The control group remained significantly $(p<.01)$ heavier than both the $1.5 \%$ and $2.7 \%$ CaP fed groups. 


\section{Figure 1. Average weight of broilers fed calcium propionate 2 weeks and finished on control feed for 6 weeks.}

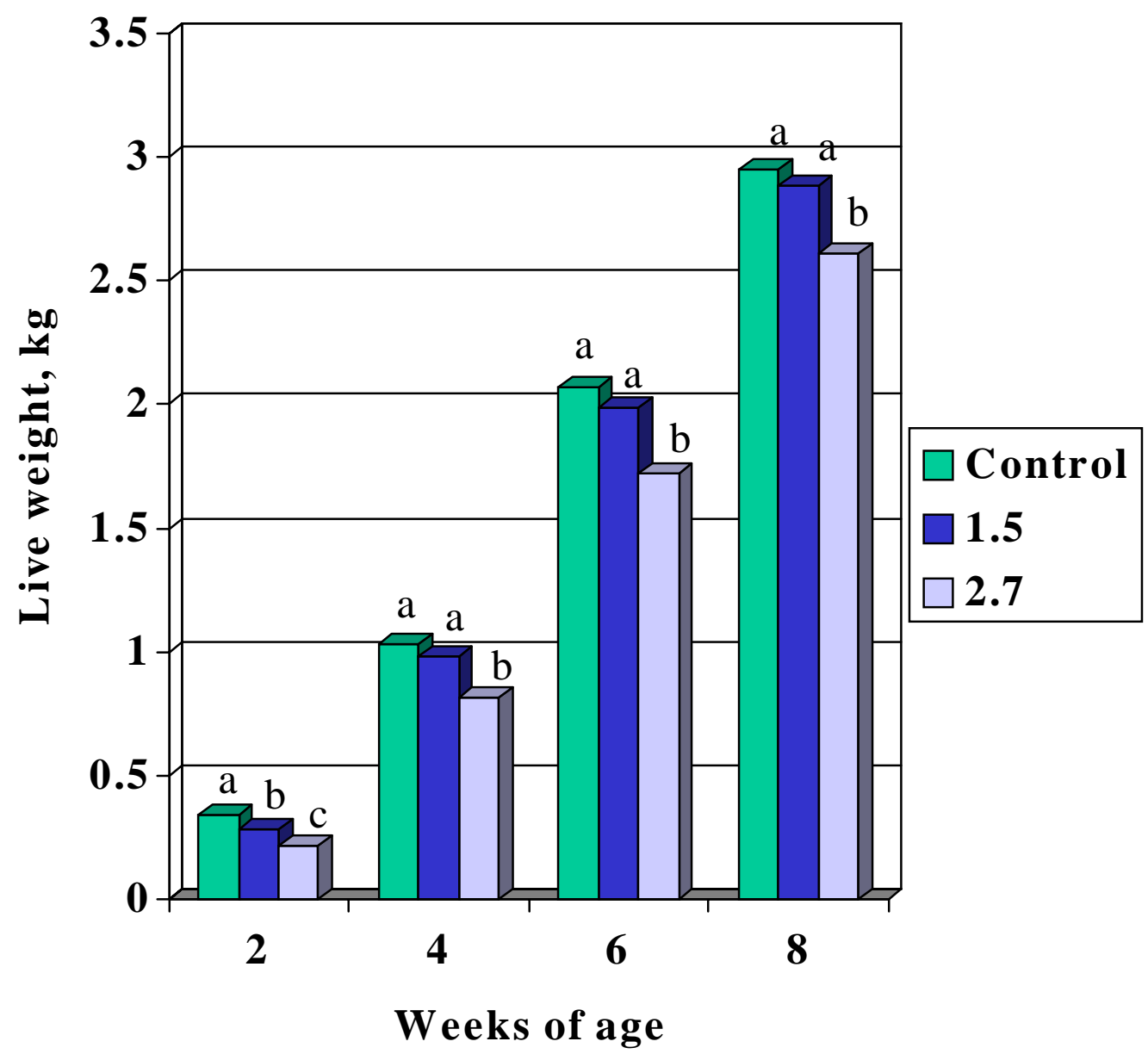

a-c least square means for each week with common superscripts do not differ significantly $(\mathrm{p}<.01)$ 


\section{Figure 2. Average weight of broilers fed calcium propionate 4 weeks and finished on control feed for 4 weeks.}

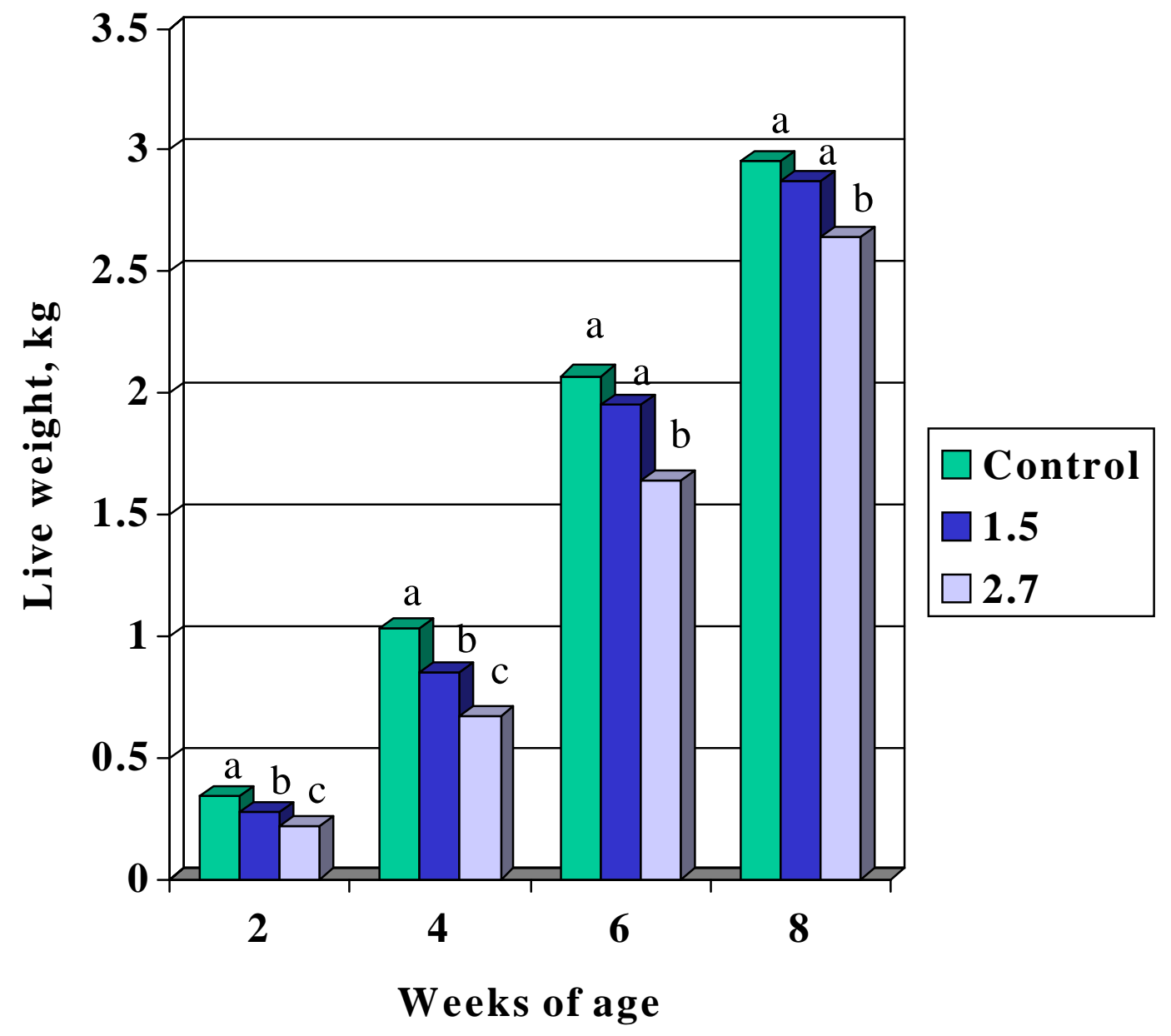

a-c least square means for each week with common superscripts do not differ significantly $(\mathrm{p}<.01)$ 


\section{Figure 3. Average weight of broilers fed calcium propionate 6 weeks and finished on control feed for 2 weeks.}

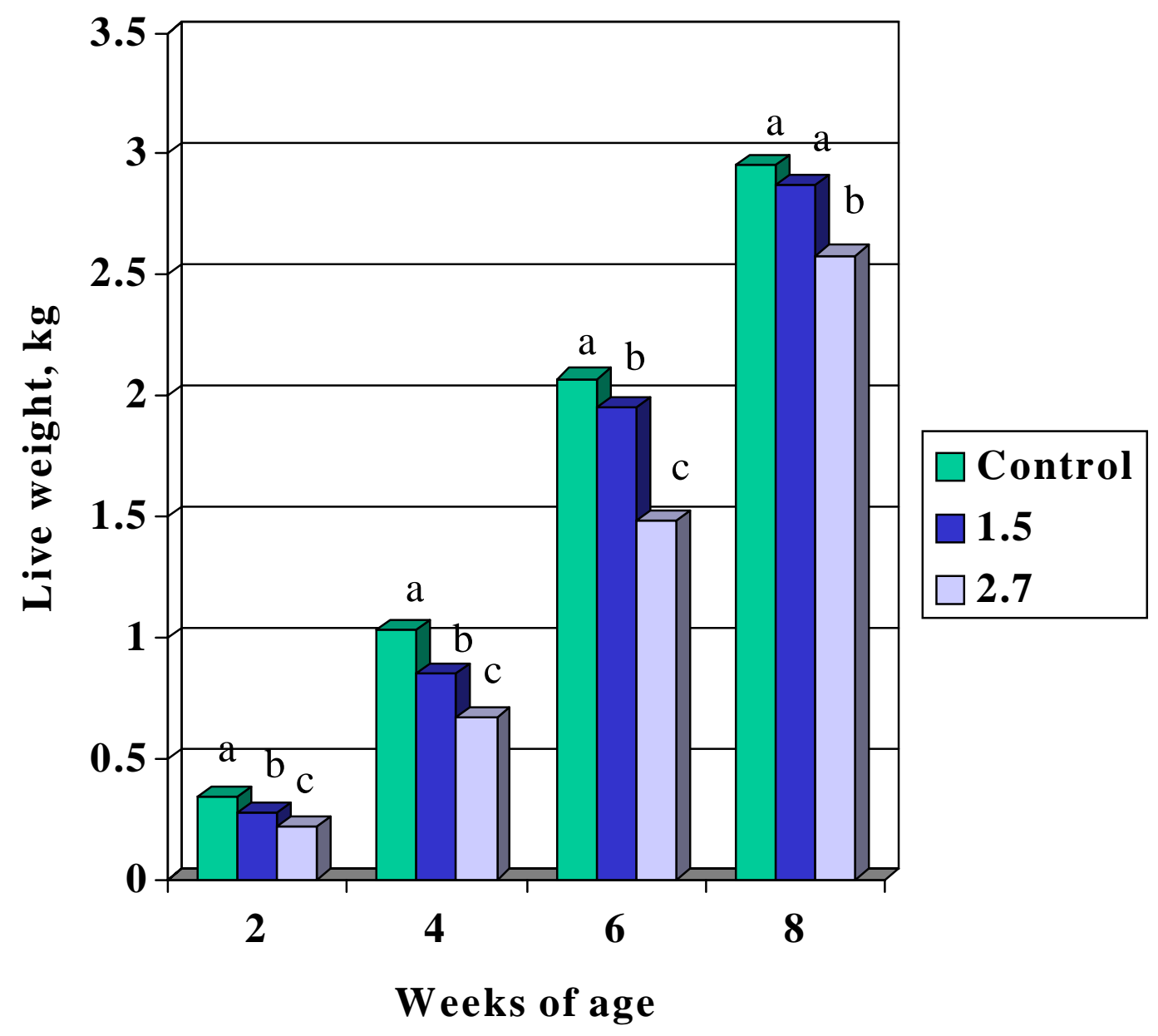

a-c least square means for each week with common superscripts do not differ significantly $(\mathrm{p}<.01)$ 


\section{Figure 4. Average weight of broilers fed calcium propionate 8 weeks.}

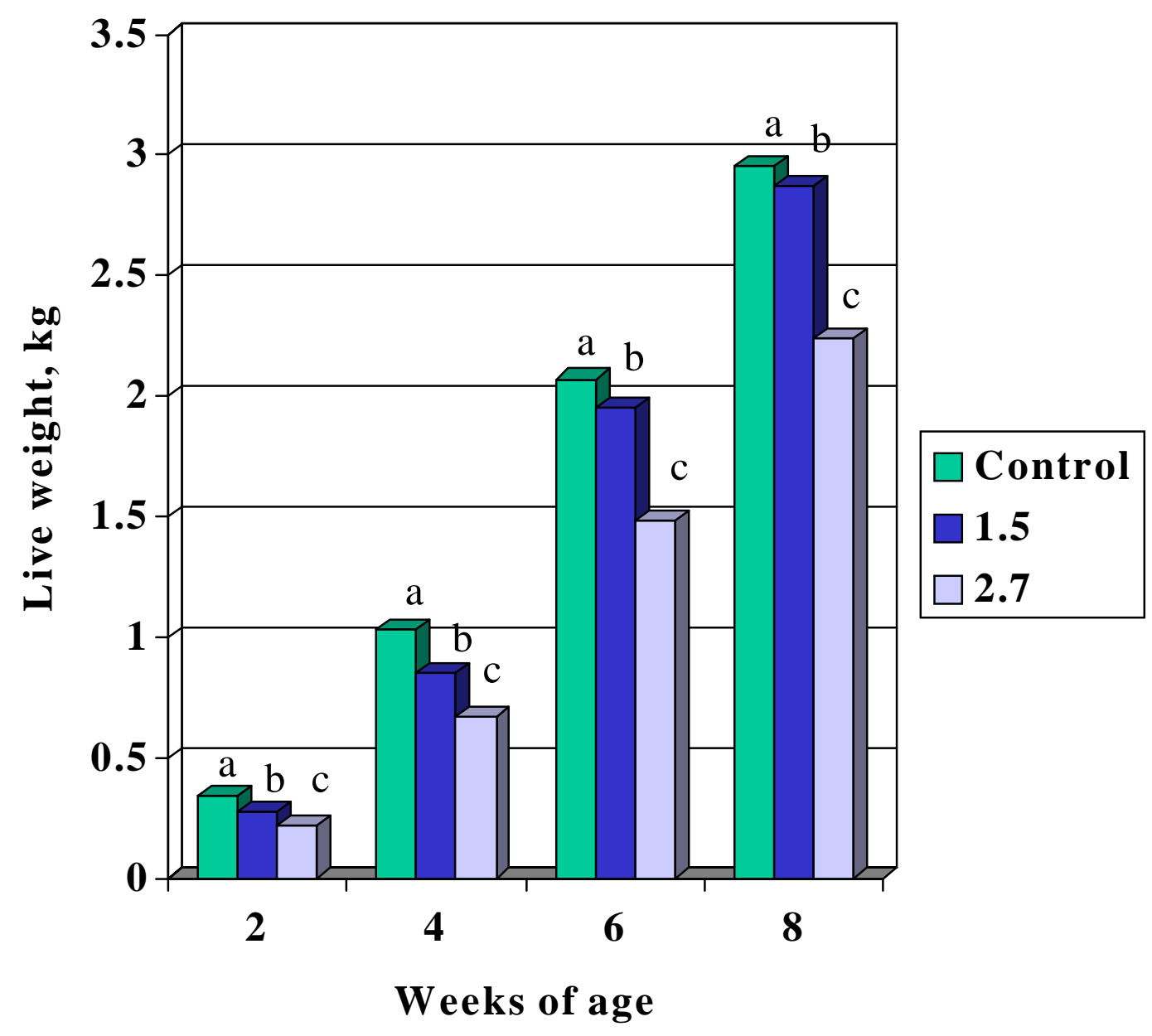

a-c least square means for each week with common superscripts do not differ significantly $(\mathrm{p}<.01)$ 


\subsection{Weight Gain}

The average weight gain of broilers fed CaP $1.5 \%$ and $2.7 \%$ and finished on control feed is shown in figures 5 through 8.

The effect of feeding calcium propionate for two weeks and then finishing on control feed is seen in figure 5 weight gain in the control fed group at 2 weeks of age was significantly $(p<.01)$ greater than the 1.5 and $2.7 \% \mathrm{CaP}$ fed groups. The $1.5 \%$ fed CaP group gained $(\mathrm{p}<.01)$ more at the end of week 4 than the $2.7 \%$ CaP fed group. At week 6 weight gain in the $1.5 \%$ and $2.7 \% \mathrm{CaP}$ fed groups was similar to that measured in the control fed group. Average weight gain for the control and treated groups were not significantly different at the end of the trial (wk 8). The data in figure 6 denotes the effect of feeding CaP for four weeks. At weeks 2 and 4 the control group gained more $(p<.01)$ than the $1.5 \%$ and 2.7\% CaP fed groups. However, at week 6 the $1.5 \% \mathrm{CaP}$ fed group gained significantly $(\mathrm{p}<.01)$ more than the control and $2.7 \%$ fed group while at week 8 the $2.7 \%$ fed group gained more $(\mathrm{p}<.01)$ more than the control and $1.5 \%$ fed group.

Figure 7 presents data showing the effect of feeding CaP for 6 weeks and then finishing on control feed. Weight gain was greatest in control fed birds at weeks 2 and 4 . At week 6 both the control and $1.5 \%$ fed groups gained significantly $(p<.01)$ more than the $2.7 \%$ fed group. At the end of the trial ( $8 \mathrm{wk}$ ) the $1.5 \%$ 
fed group gained more than the control and 2.7\% fed groups. The effect of feeding calcium propionate for eight weeks is shown in figure 8. Control fed birds gained more weight at weeks 2 and 4. At 6 weeks of age weight gain in the 1.5\% group was the same as in control fed birds while at week 8 weight gain was similar between control and treated groups.

The average 8-week feed to gain ratios of broilers fed CaP supplemented feed for either $2,4,6$, or 8 weeks is shown in figure 9. Broilers fed $1.5 \%$ and $2.7 \%$ CaP for two weeks, then finished on a control feed were not significantly different from the controls. Broilers fed $1.5 \% \mathrm{CaP}$ for 4,6 , and 8 weeks, then finished on control feed had a significantly $(\mathrm{p}<.01)$ higher feed to gain ratios than the broilers fed 2.7\% CaP supplemented feed. The control group had a significantly $(\mathrm{p}<.01)$ higher feed to gain ratios than either the $1.5 \%$ or $2.7 \% \mathrm{CaP}$ fed groups at weeks 4,6, and 8 . 
Figure 5. Average weight gain of broilers fed calcium propionate 2 weeks and
finished on control feed for 6 weeks.

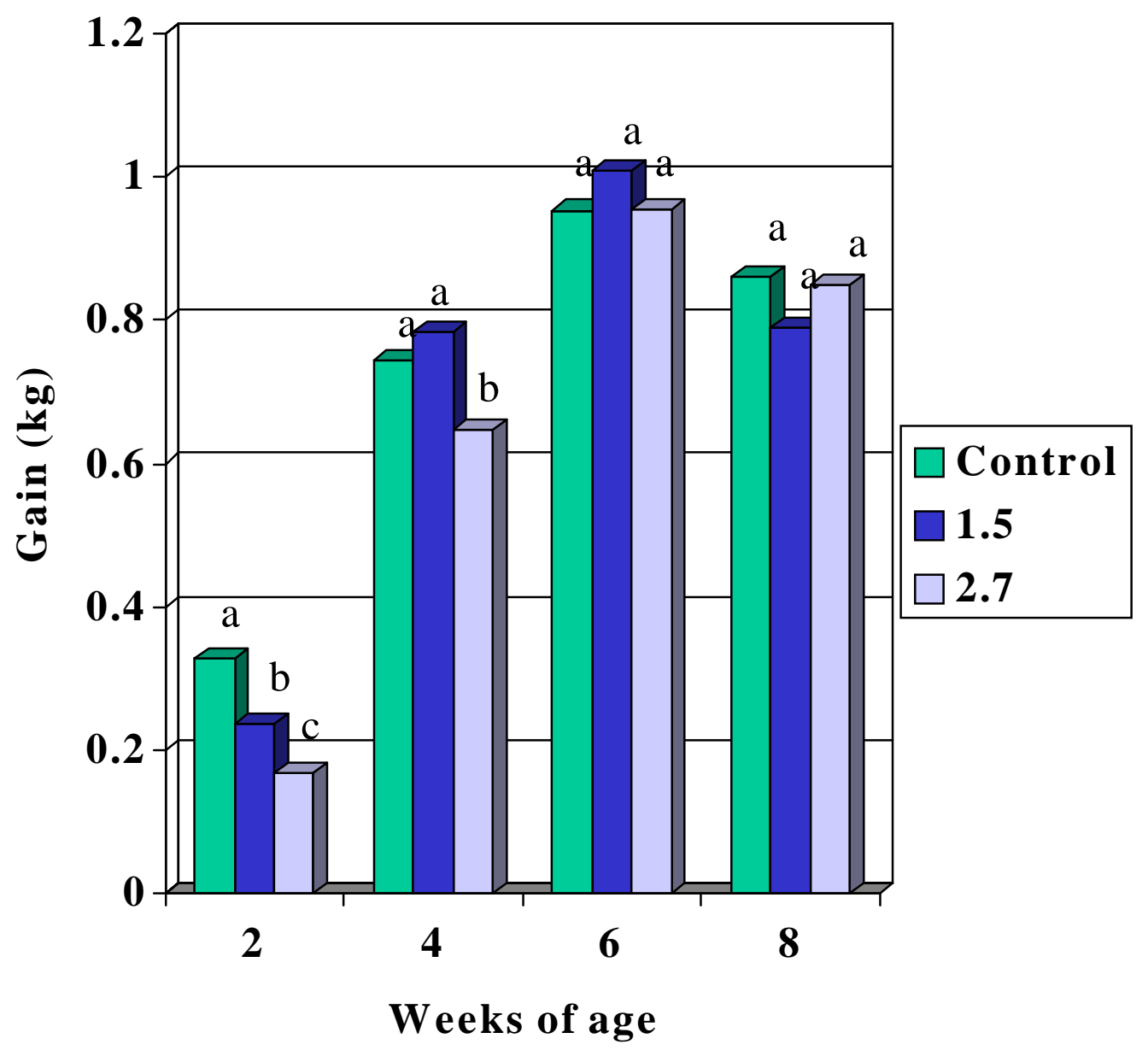

a-c least square means for each week with common superscripts do not differ significantly $(\mathrm{p}<.01)$ 
Figure 6. Average weight gain of broilers fed calcium propionate 4 weeks and
finished on control feed for 4 weeks.

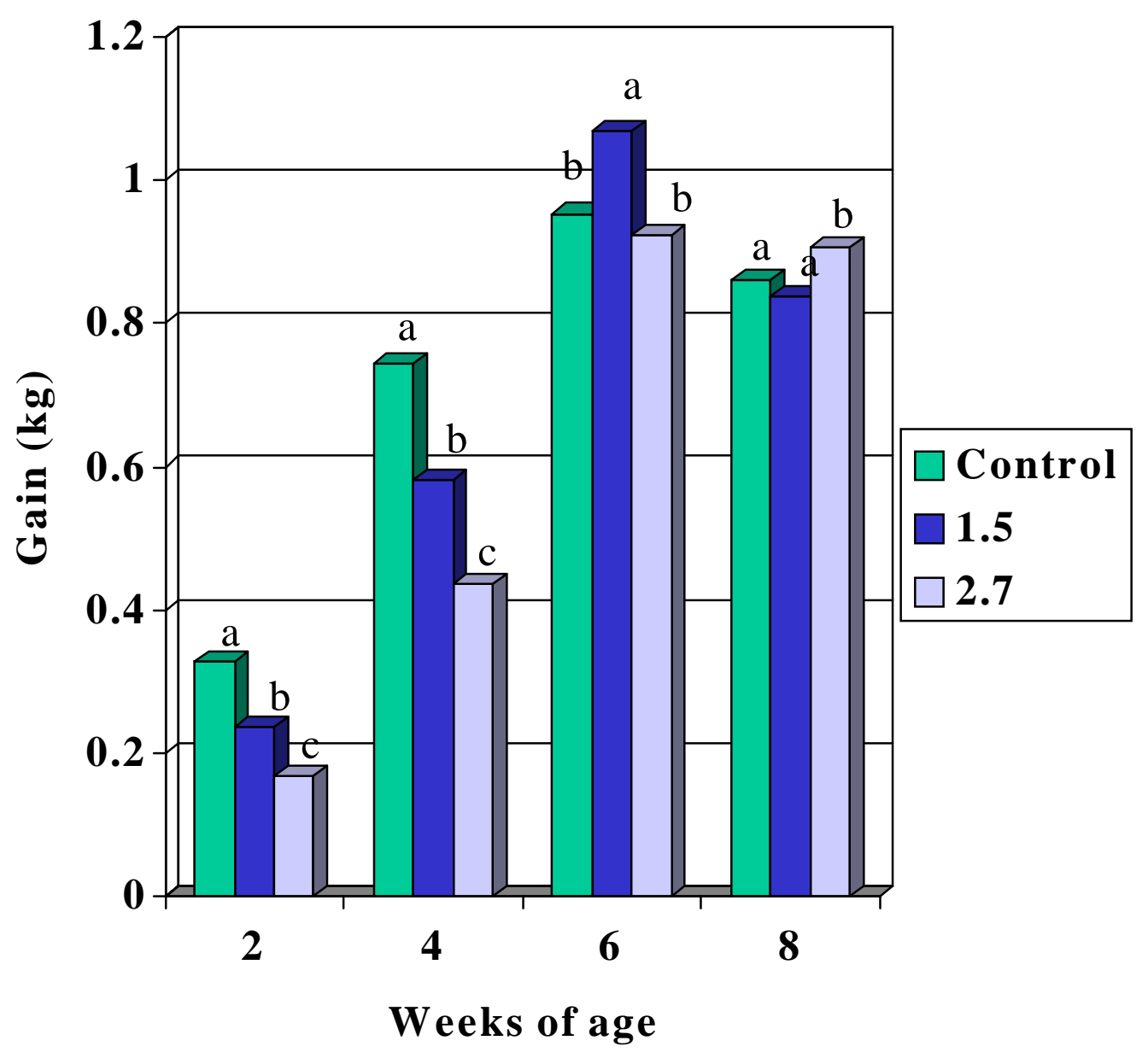

a-c least square means for each week with common superscripts do not differ significantly $(\mathrm{p}<.01)$ 
Figure 7. Average weight gain of broilers fed calcium propionate 6 weeks and
finished on control feed for 2 weeks.

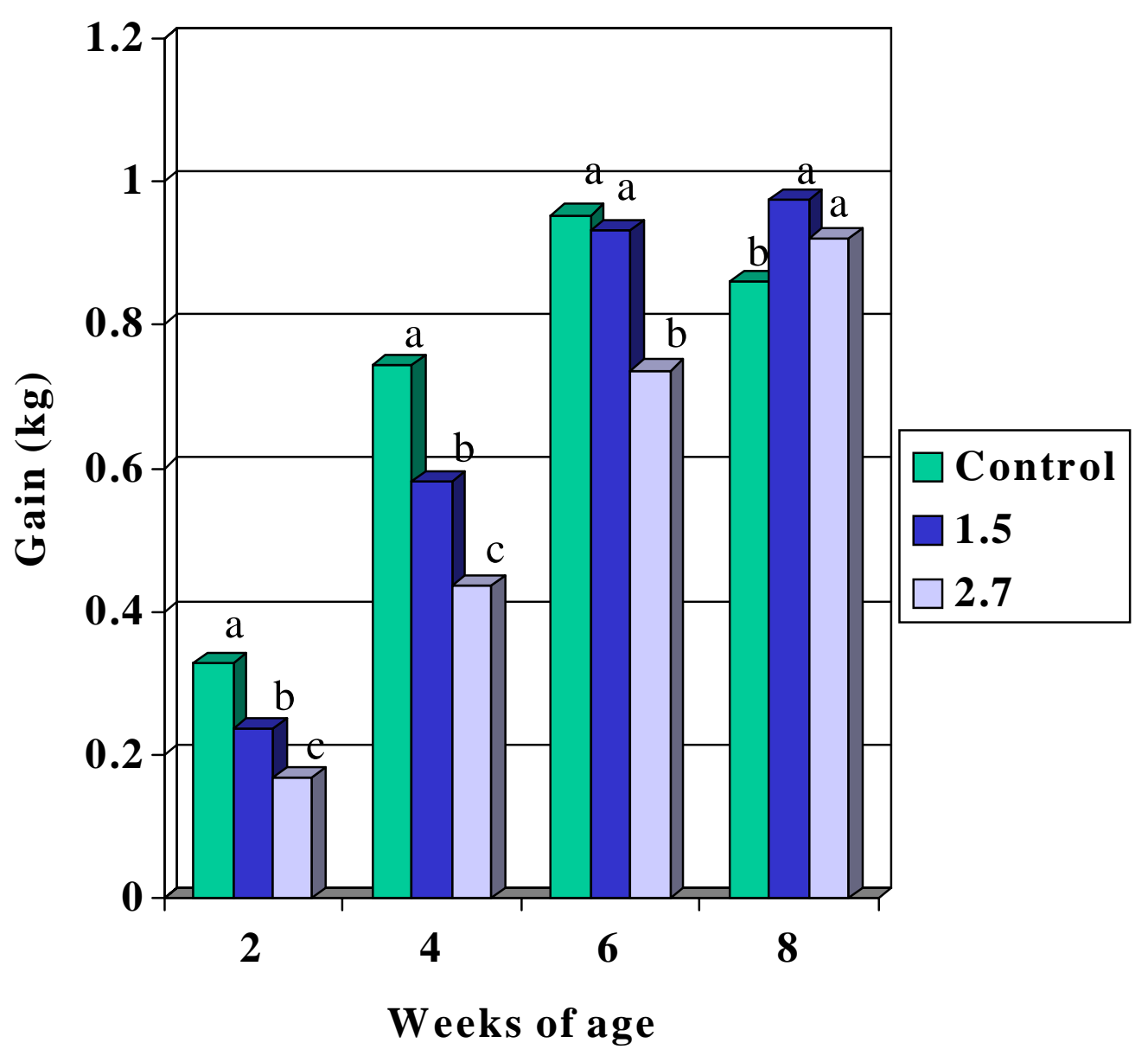

a-c least square means for each week with common superscripts do not differ significantly $(\mathrm{p}<.01)$ 


\section{Figure 8. Average weight gain of broilers fed calcium propionate for 8 weeks.}

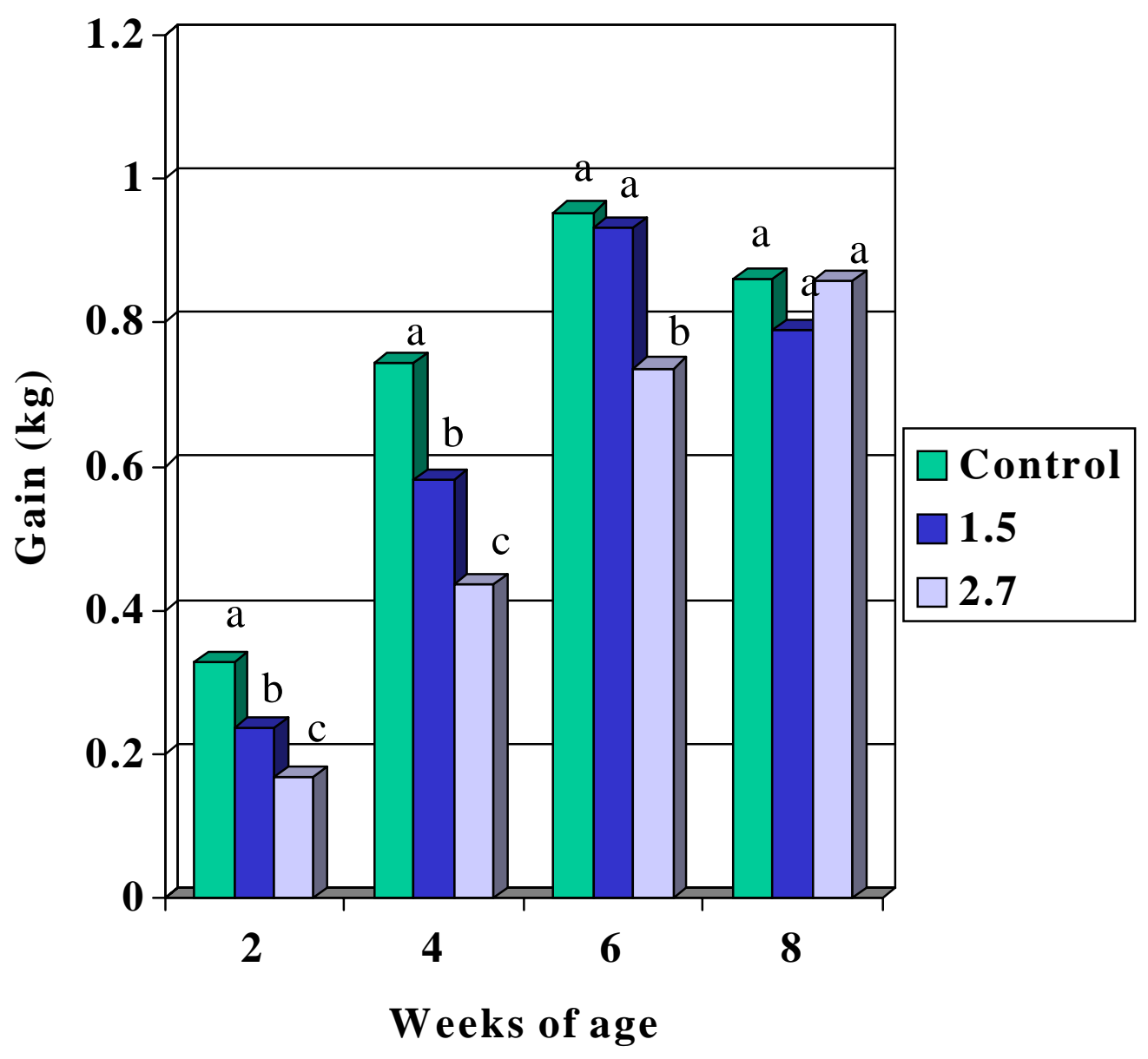

a-c least square means for each week with common superscripts do not differ significantly $(\mathrm{p}<.01)$ 


\section{Figure 9. Average 8 week feed to gain ratio of broilers fed calcium propionate at $1.5 \%$ and $2.7 \%$ and finished on control feed .}

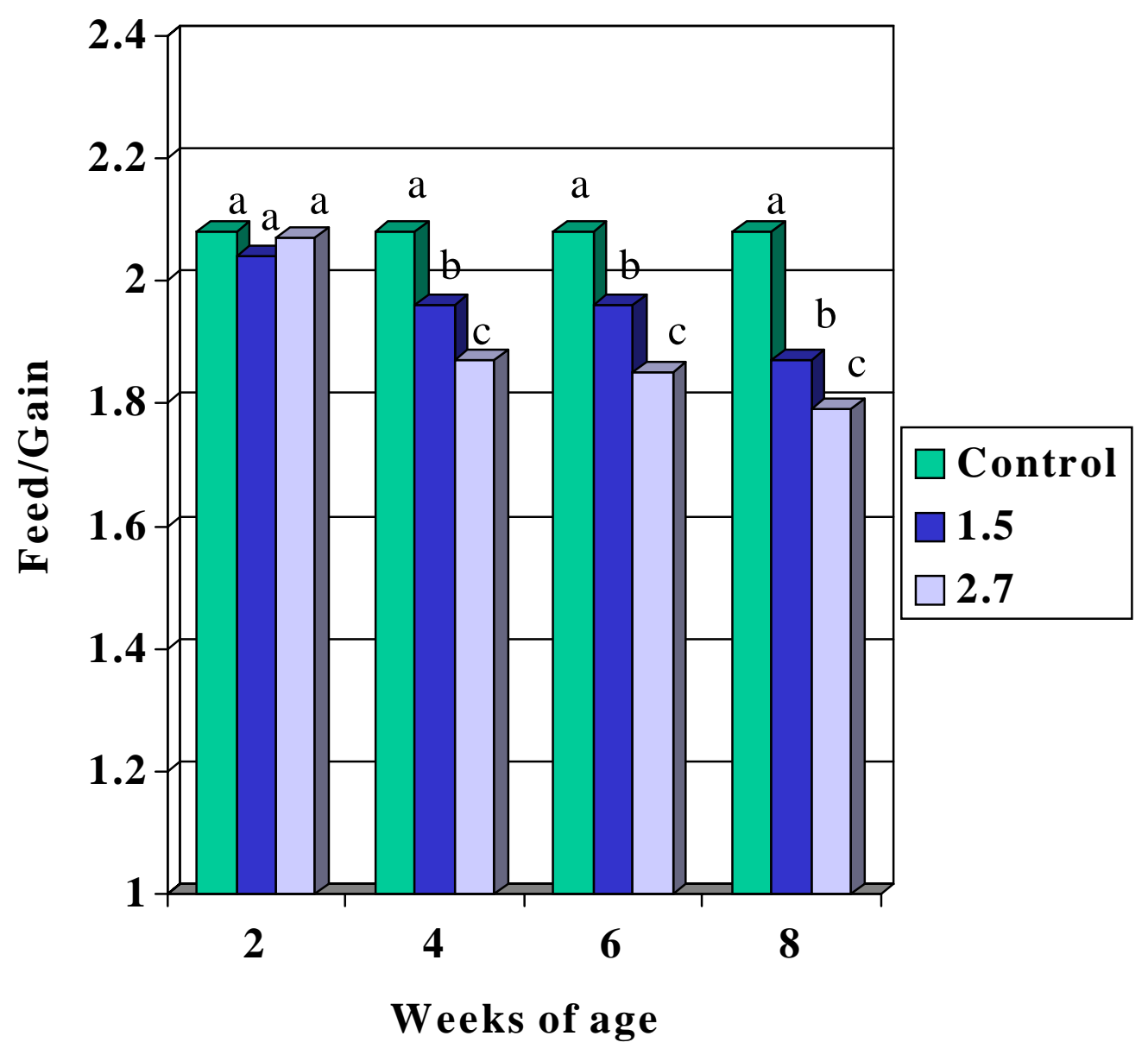

a-c least square means for each week with common superscripts do not differ significantly $(\mathrm{p}<.01)$ 


\subsection{Carcass fat, fat pad weights and carcass protein}

Figure 10 shows the percent carcass fat, fat pad weights and percent carcass fat of eviscerated 8 week old broilers fed CaP. Broilers fed $1.5 \%$ and $2.7 \% \mathrm{CaP}$ for the first 2 weeks after hatch had significantly $(p<.01)$ less carcass fat than the control group when analyzed at 8 weeks of age. The four week treated groups fed 1.5\% CaP had significantly $(p<.01)$ more fat than either the control and 2.7\% CaP groups. However, the group fed 2.7\% CaP had significantly $(\mathrm{p}<.01)$ less carcass fat than the control and the 1.5\% CaP group. The six and eight week treatment groups fed 1.5\% and $2.7 \% \mathrm{CaP}$ had a dose dependent decrease $(\mathrm{p}<.01)$ in carcass fat compared to control broilers. Figure 11 shows the fat pad weights of eviscerated 8 week old broilers fed CaP for either 2,4,6, or 8 weeks. The fat pads in the 2-week CaP treated groups were lower in weight $(\mathrm{p}<.01)$ than the birds fed a control diet. There were no differences in fat pad weights in birds in the control and the 1.5\% CaP fed birds from the 4 and 8 week treated groups. However, in the 6 week treated group a reversal occurred in that the fat pad from the control was less $(p<.01)$ than that measured in the $1.5 \% \mathrm{CaP}$ fed broilers. The fat pads of the eviscerated 8 week old broilers fed CaP at $2.7 \%$ for 8 weeks were lower $(p .<01)$ than controls and the $1.5 \%$ CaP treated broilers. 
The percent carcass protein of eviscerated 8 week old broilers fed CaP for either 2,4,6, or 8 weeks is shown in figure12. Overall, the $2,4.6$ or $2.7 \% \mathrm{CaP}$ had $\mathrm{p}<.05)$ more carcass protein than the control fed birds. 


\section{Figure 10. Percent carcass fat of eviscerated 8 week old broilers fed calcium propionate at $1.5 \%$ and $2.7 \%$ and finished on control feed.}

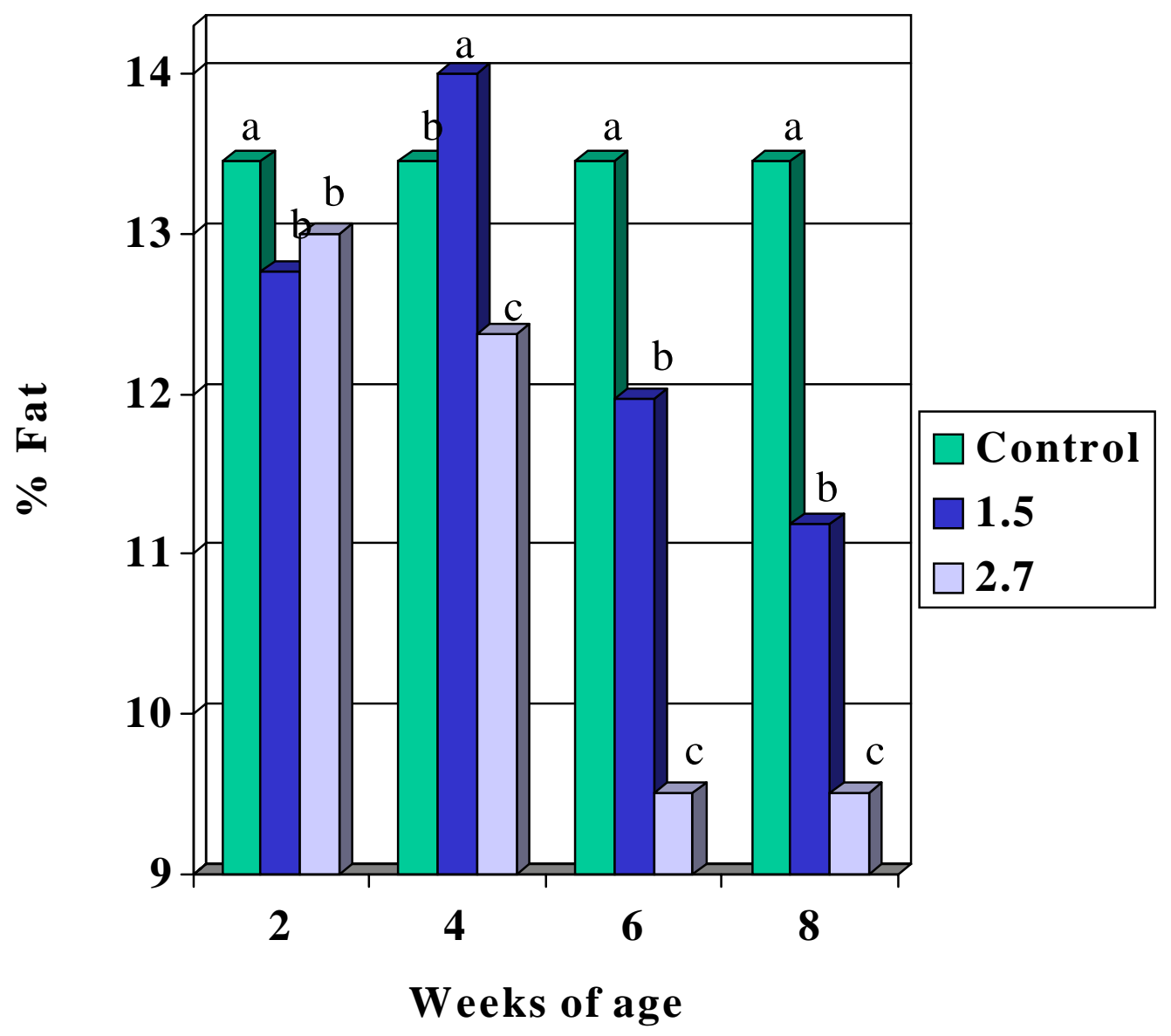

a-c least square means for each week with common superscripts do not differ significantly $(\mathrm{p}<.01)$ 


\section{Figure 11. Fat pad weight of eviscerated 8 week old broilers fed calcium propionate at $1.5 \%$ and $2.7 \%$ and finished on control feed.}

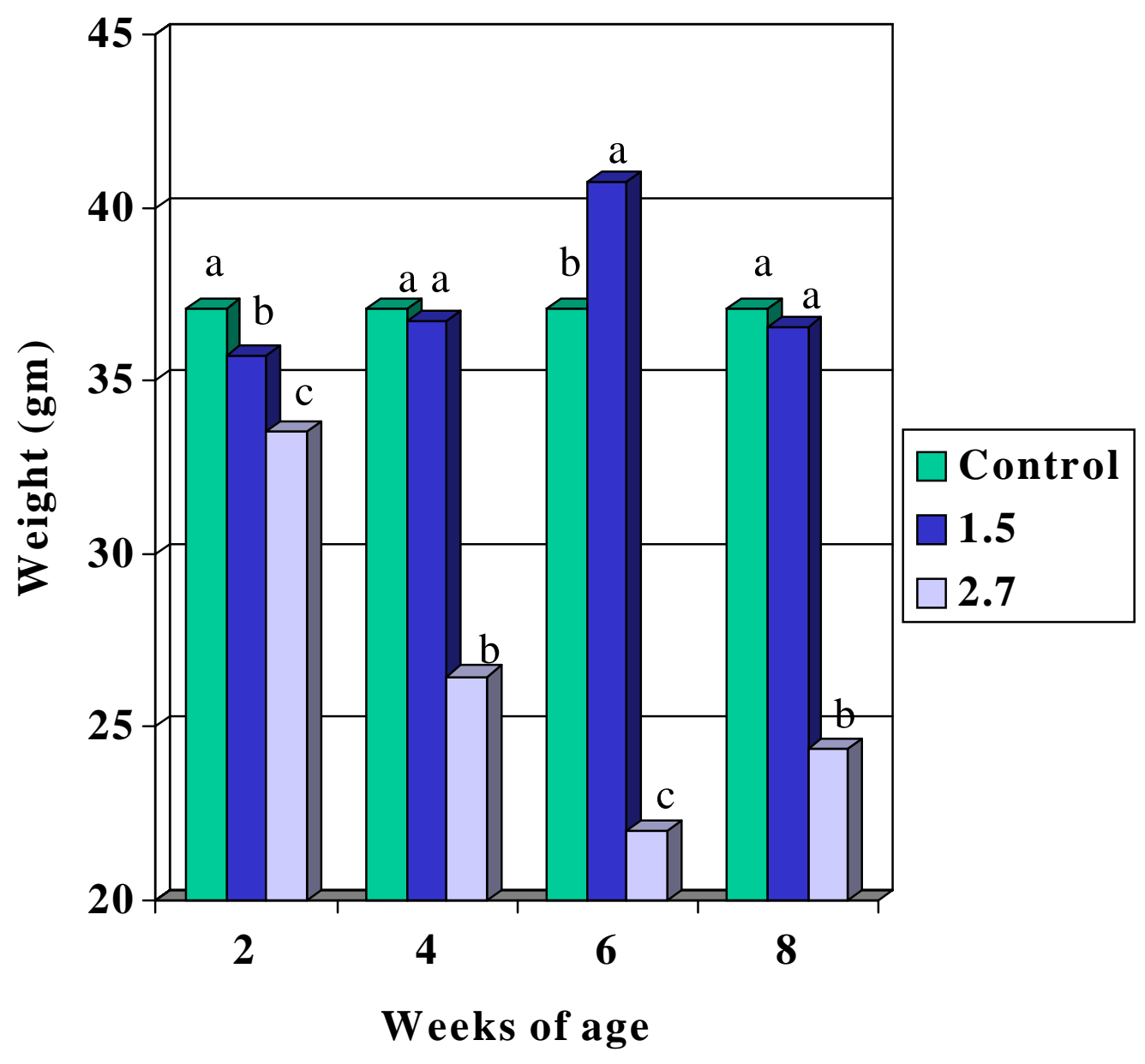

a-c least square means for each week with common superscripts do not differ significantly $(\mathrm{p}<.01)$ 


\section{Figure 12. Percent protein of eviscerated 8 week old broilers fed calcium propionate at $1.5 \%$ and $2.7 \%$ and finished on control feed.}

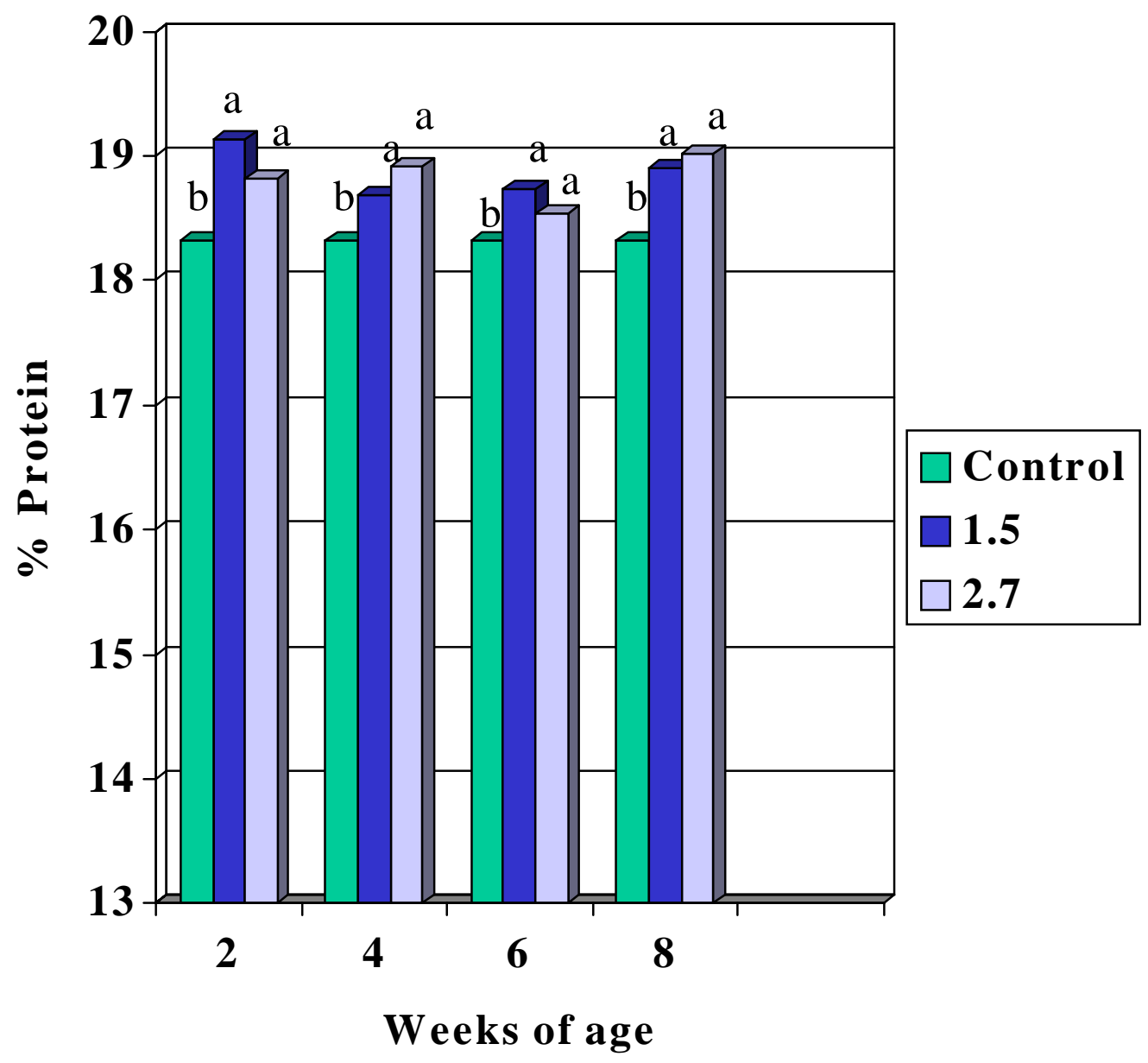

a-c least square means for each week with common superscripts do not differ significantly $(\mathrm{p}<.01)$ 


\subsection{Live and Dressed Carcass Weight}

The live weights of 8 week old broilers that were slaughtered and used for carcass analysis are shown in Figure 13. The weights of these broilers are comparable to those previously observed. There was a dose dependent decrease in body weight that become more pronounced with the duration of feeding CaP. Controls were similar in body weight to birds fed $1.7 \%$ CaP for two weeks but were lower $(p<.01)$ in birds fed $2.7 \%$ CaP for 2 weeks. Live weights were lower $(p<.01)$ in treatment groups at weeks 4,6 and 8 . The dressed carcass weights of these 8 week old broilers slaughtered for carcass analysis is shown in Figure 14. Controls were similar in dressed weight only to the birds treated with $1.5 \%$ CaP for 2 weeks and were different $(p<.01)$ in the 4,6 and 8 week treatment regimes. The $2.7 \%$ fed group was lower $(\mathrm{p}<.01)$ than either the control or $1.5 \%$ groups at each time point. 
Figure 13. Live weights of 8 week old broilers slaughtered for carcass analysis and fed calcium propionate at $1.5 \%$ and $2.7 \%$ and finished on control feed.

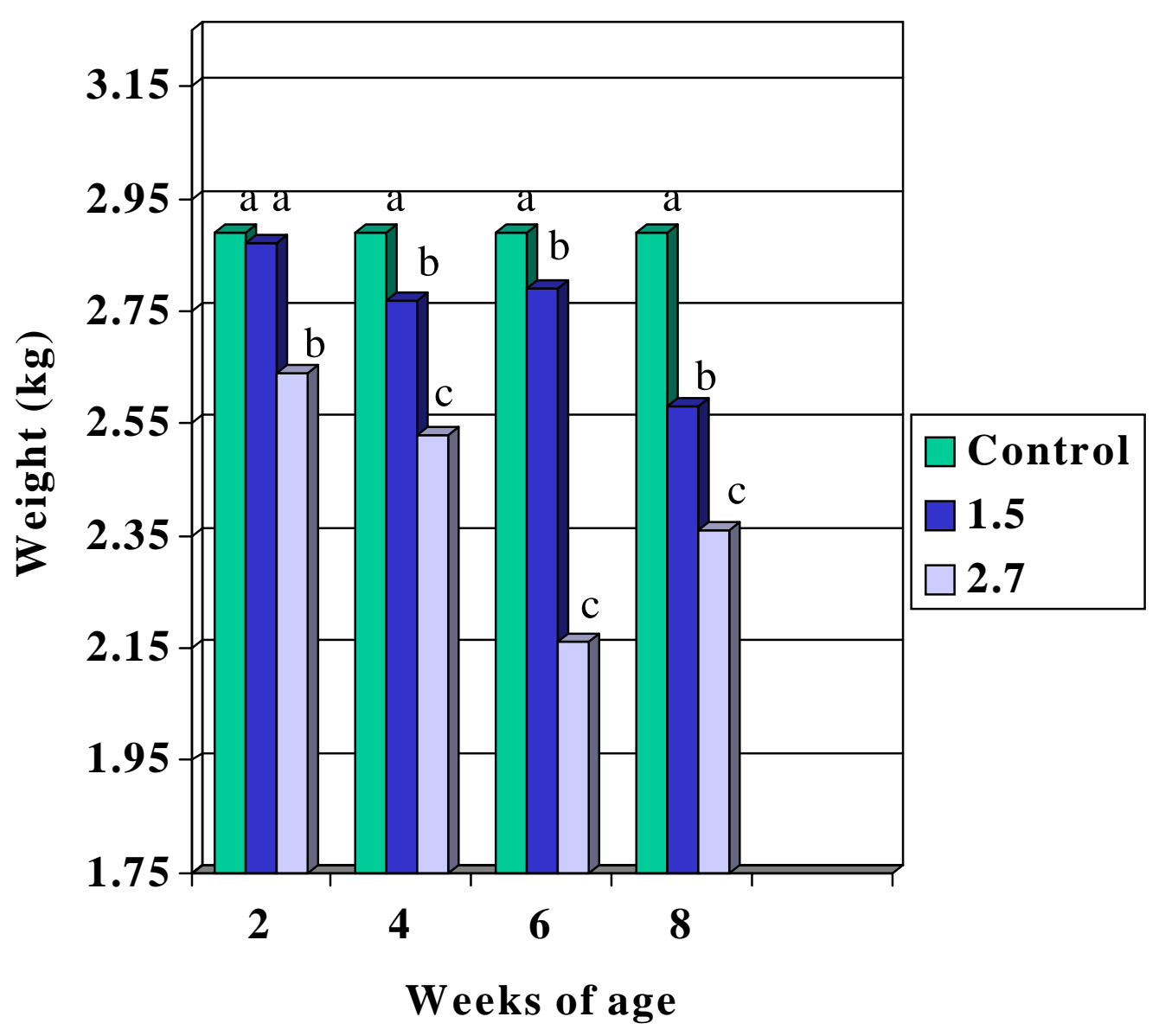

a-c least square means for each week with common superscripts do not differ significantly $(\mathrm{p}<.01)$ 


\section{Figure 14. Dressed carcass weight of 8 week old broilers slaughtered for carcass analysis and fed calcium propionate at $1.5 \%$ and $2.7 \%$ and finished on control feed.}

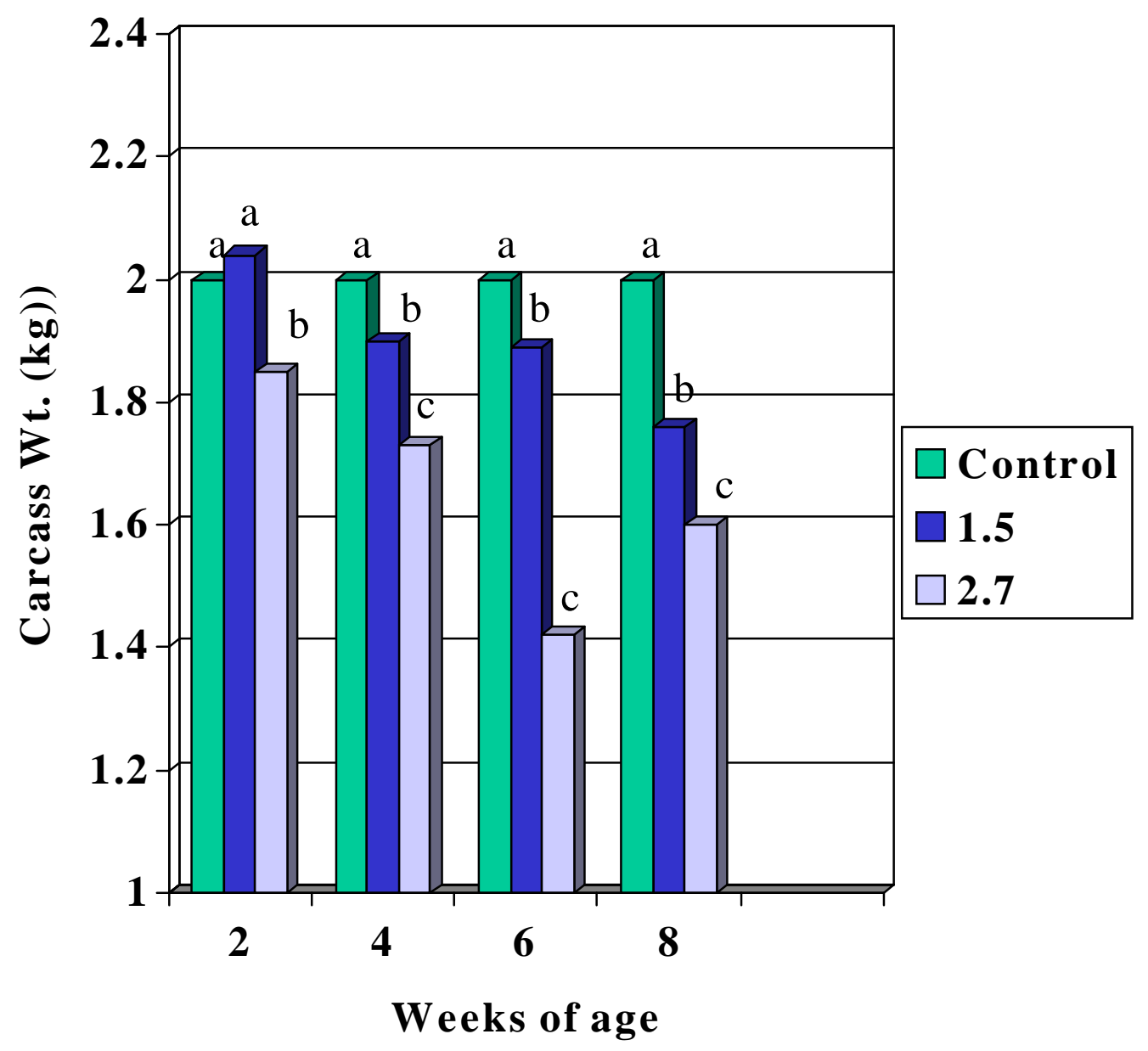

a-c least square means for each week with common superscripts do not differ significantly $(\mathrm{p}<.01)$ 


\subsection{Plasma Growth Hormone and Glucose}

Plasma growth hormone (GH) levels of broilers fed CaP at $1.5 \%$ and $2.7 \%$ shown in figures 15-19.

The concentration of plasma $\mathrm{GH}$ of broilers fed calcium propionate for the first two weeks is seen in figure 15. At week 4 concentrations of plasma $\mathrm{GH}$ in the 2.7\% $\mathrm{CaP}$ fed group were $(\mathrm{p}<.01)$ higher than the $1.5 \%$ and control group. At both weeks 6 and 8 concentrations of plasma $\mathrm{GH}$ in the 2.7\% CaP fed groups remained $(\mathrm{p}<.01)$ higher than $1.5 \%$ and control groups, while the 1.5\% CaP birds were $(\mathrm{p}<.01)$ higher than the control at weeks 6 and 8 .

The data in figure 16 shows concentrations of plasma GH in broilers fed CaP for 4 weeks. At weeks 4,6, and 8 there was adose-related increase $(\mathrm{p}<.01)$ in plasma concentrations of $\mathrm{GH}$ as compared to the control group.

Figure 17 shows the GH levels in broilers fed CaP for the first 6 weeks. At weeks 4,6 , and 8 there was a dose-related increase $(p<.01)$ over the control group.

The GH levels of broilers fed CaP for all 8 weeks of the trial is seen in figure 18. At weeks 4,6, and 8 there was a doserelated increase $(\mathrm{p}<.01)$ in concentrations of plasma GH over the control groups.

The average plasma glucose levels of broilers fed CaP at two 
levels $1.5 \%$ and $2.7 \%$ are shown in figures 19-22. Plasma glucose levels were measured in broilers fed CaP for 2 weeks (figure 19). At weeks 4,6, and 8 of age, there was a dose-related increase $(p<.01)$ glucose concentrations as compared to the control group. At 8 weeks of age there was no difference between the $1.5 \%$ and 2.7\% CaP fed broilers; however they were both $(\mathrm{p}<.01)$ higher than the control group.

The plasma glucose levels of broilers fed CaP for 4 weeks are shown in figure 20. At weeks 4,6, and 8 there was a moderate increase in the concentration of plasma glucose, which was evident at the highest dose of CaP.

Figure 21 presents the plasma glucose levels of broilers fed CaP for 6 weeks and then finished on control feed. At weeks 4,6, and 8 there was an increase $(p<.01)$ in concentrations of glucose the 2.7\% CaP fed groups as compared to the control group.

The plasma glucose levels of broilers fed CaP for the entire 8 week of the trial is seen in figure 22. In comparison with previous studies there was a more pronounced dose-related increase in concentrations of plasma glucose compared to the control groups. 


\section{Figure 15. Concentrations of plasma growth hormone in broilers fed calcium propionate for the first 2 weeks and finished on control feed.}

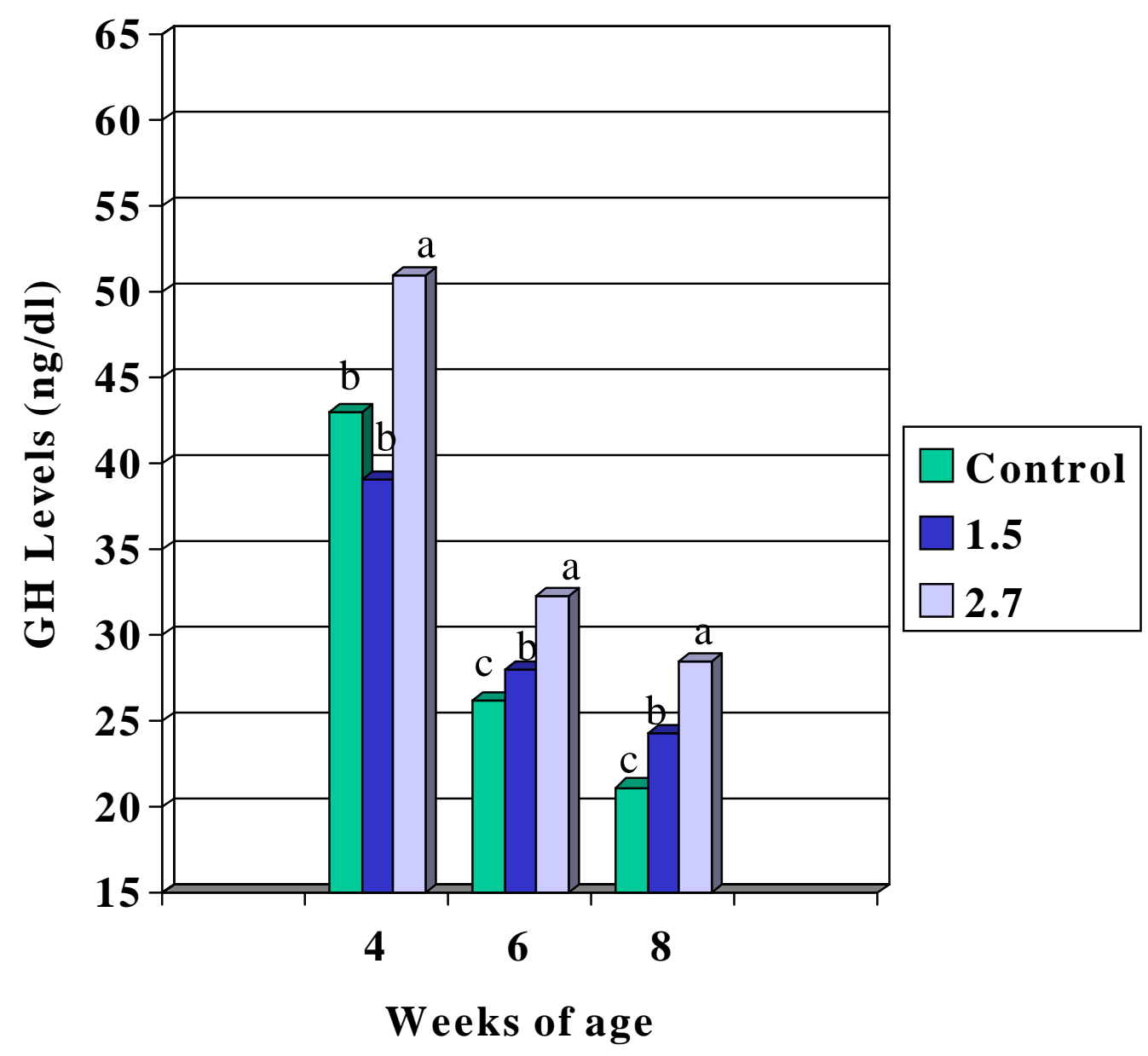

a-c least square means for each week with common superscripts do not differ significantly $(\mathrm{p}<.01)$ 


\section{Figure 16. Concentrations of plasma growth hormone in broilers fed calcium propionate for the first 4 weeks and finished on control feed.}

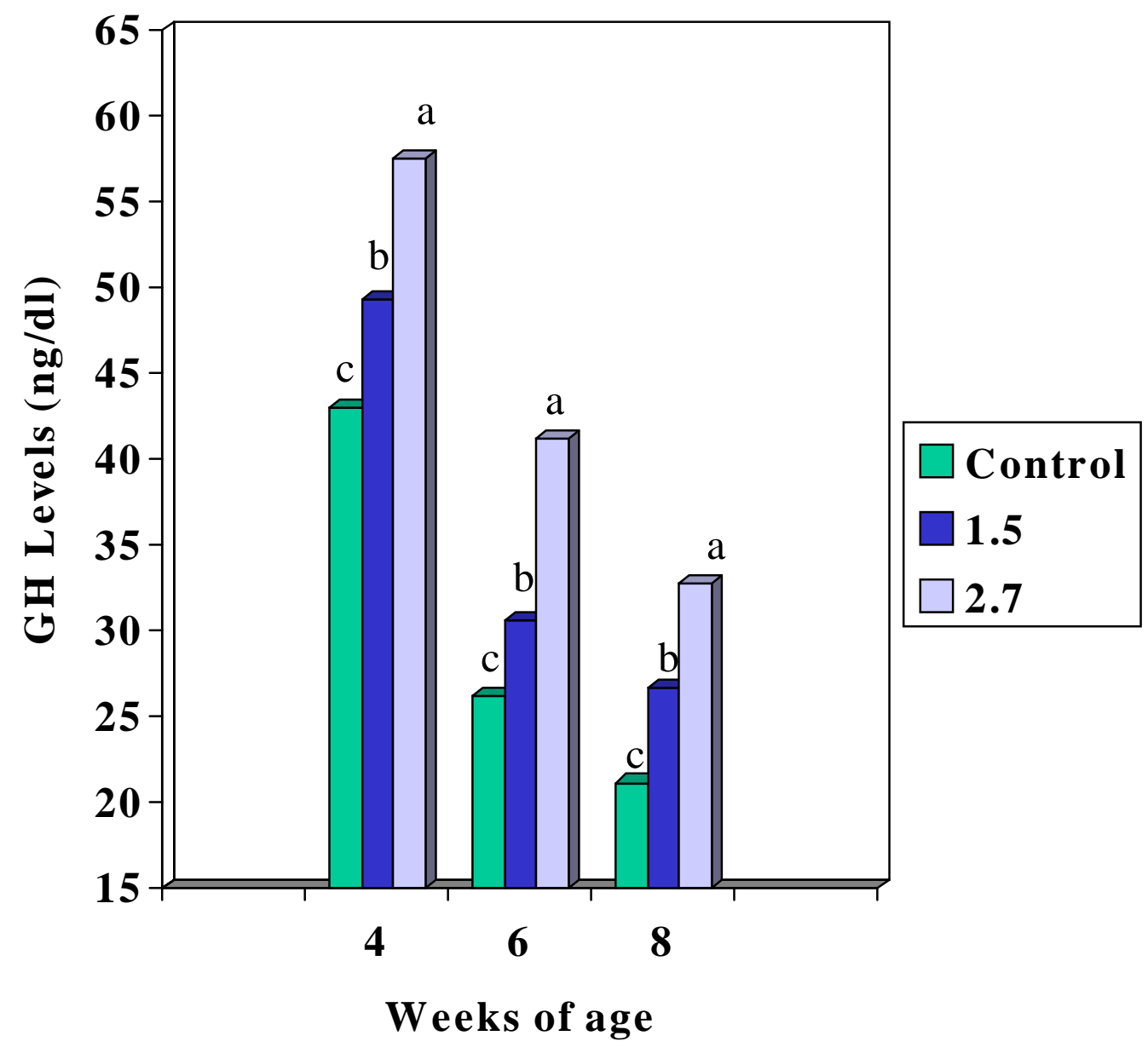

a-c least square means for each week with common superscripts do not differ significantly $(\mathrm{p}<.01)$ 


\section{Figure 17. Concentrations of plasma growth hormone in broilers fed calcium propionate for the first 6 weeks and finished on control feed.}

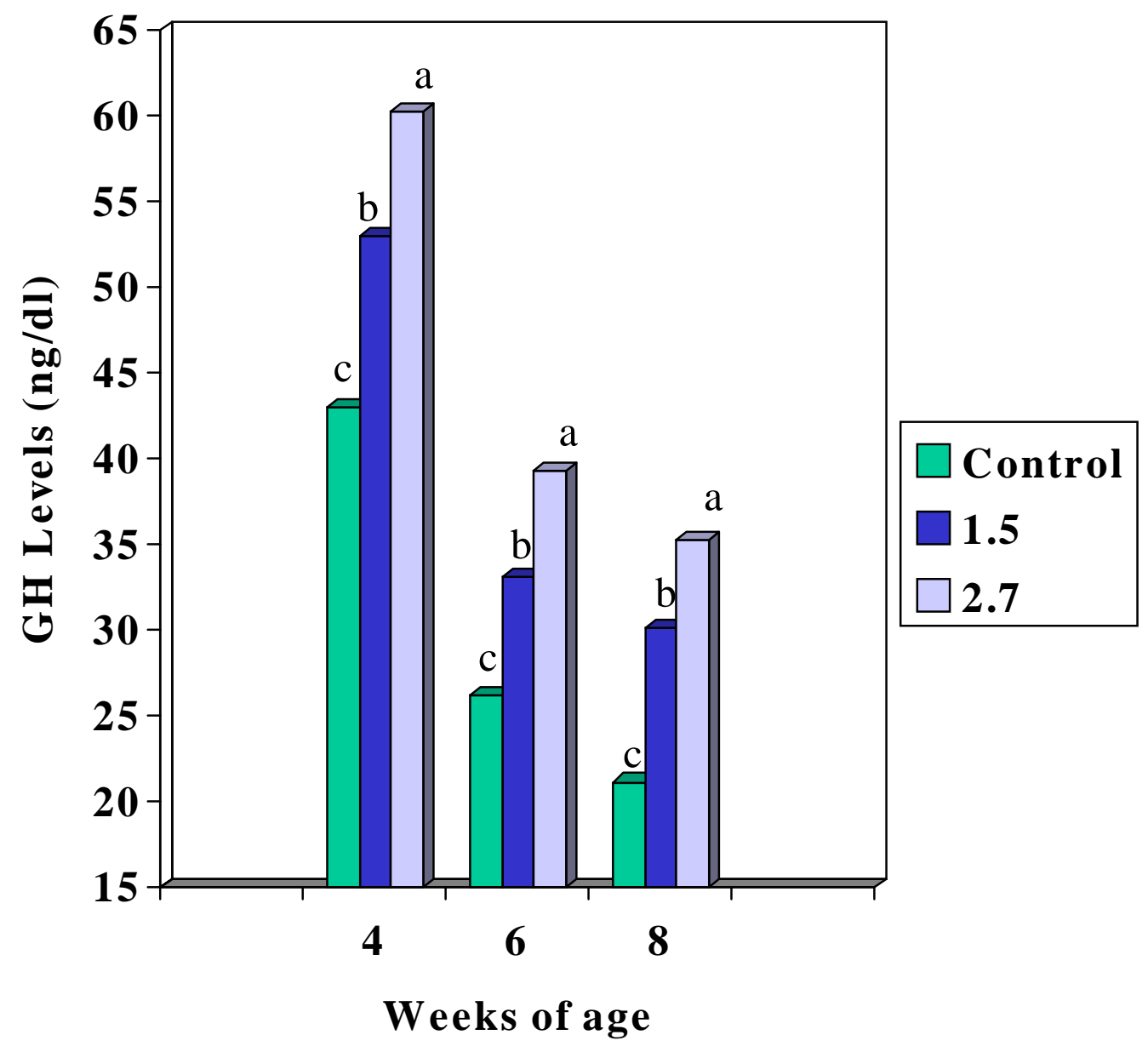

a-c least square means for each week with common superscripts do not differ significantly $(\mathrm{p}<.01)$ 


\section{Figure 18. Concentrations of plasma growth hormone in broilers fed calcium propionate for 8 weeks.}

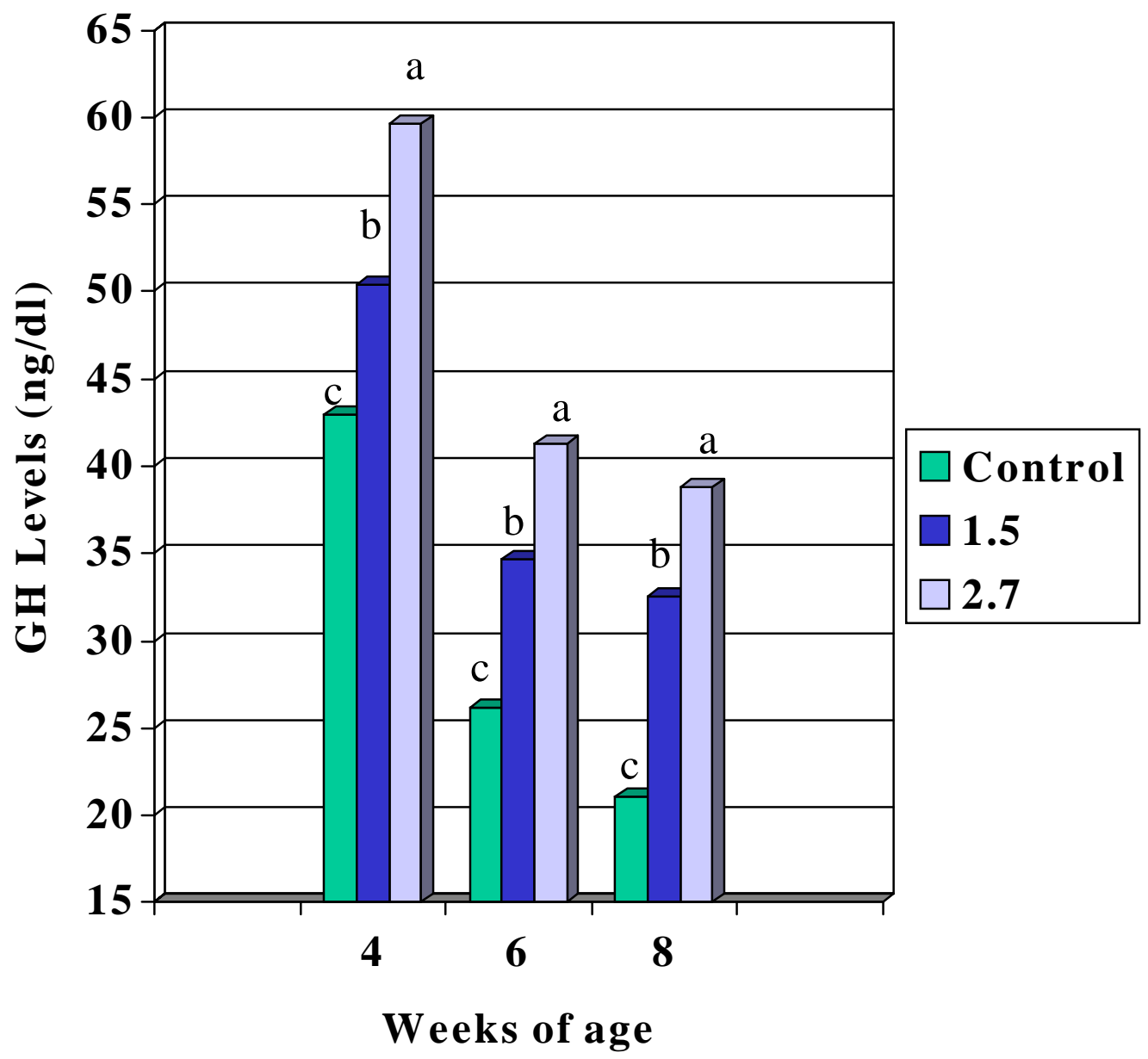

a-c least square means for each week with common superscripts do not differ significantly $(\mathrm{p}<.01)$ 
Figure 19. Average plasma glucose levels of broilers fed calcium propionate at $1.5 \%$ and $2.7 \%$ for 2 weeks and finished on control feed for 6 weeks.

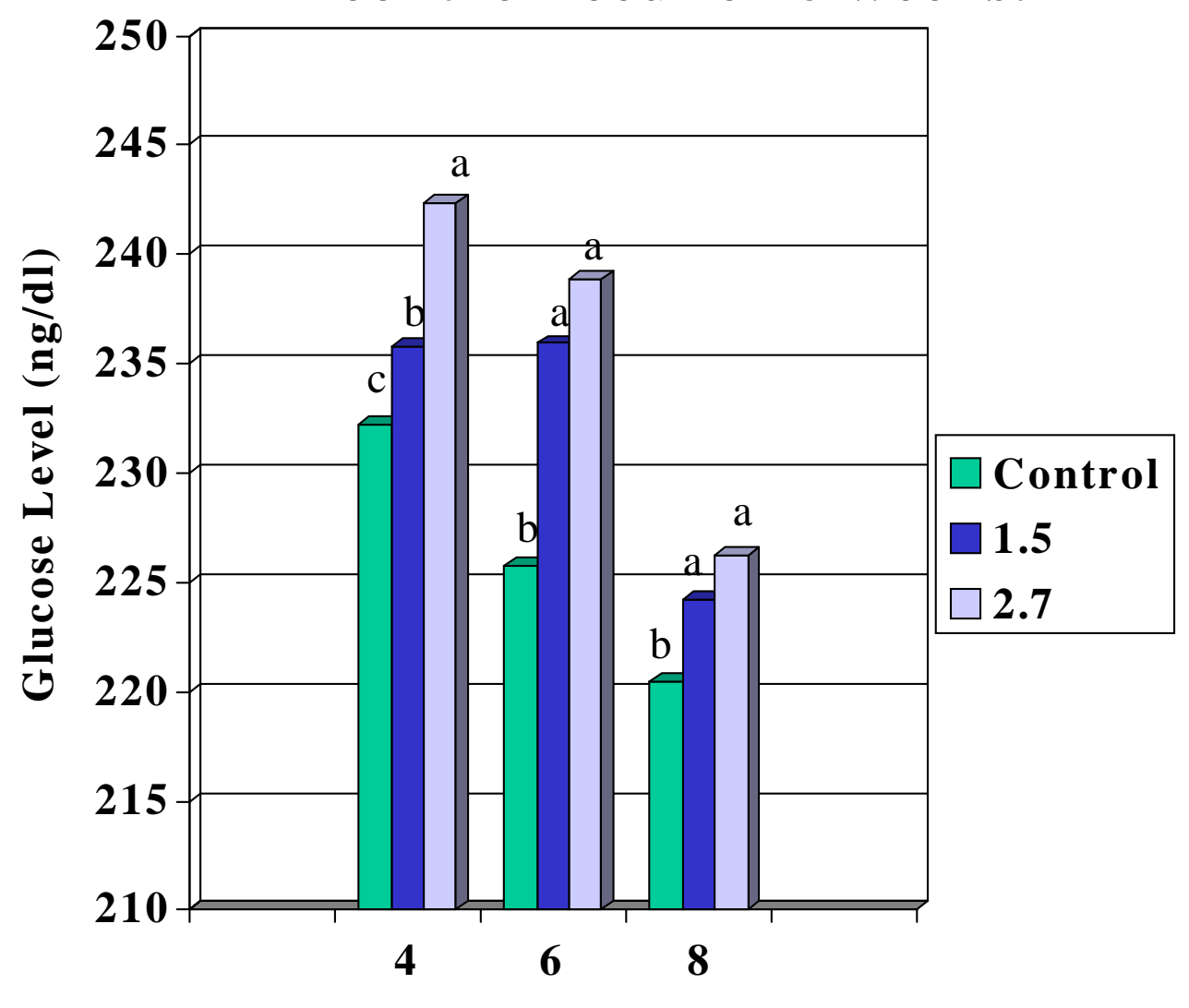

Weeks of age

a-c least square means for each week with common superscripts do not differ significantly $(\mathrm{p}<.01)$ 
Figure 20. Average plasma glucose levels of broilers fed calcium propionate at $1.5 \%$ and $2.7 \%$ for 4 weeks and finished on control feed for 4 weeks.

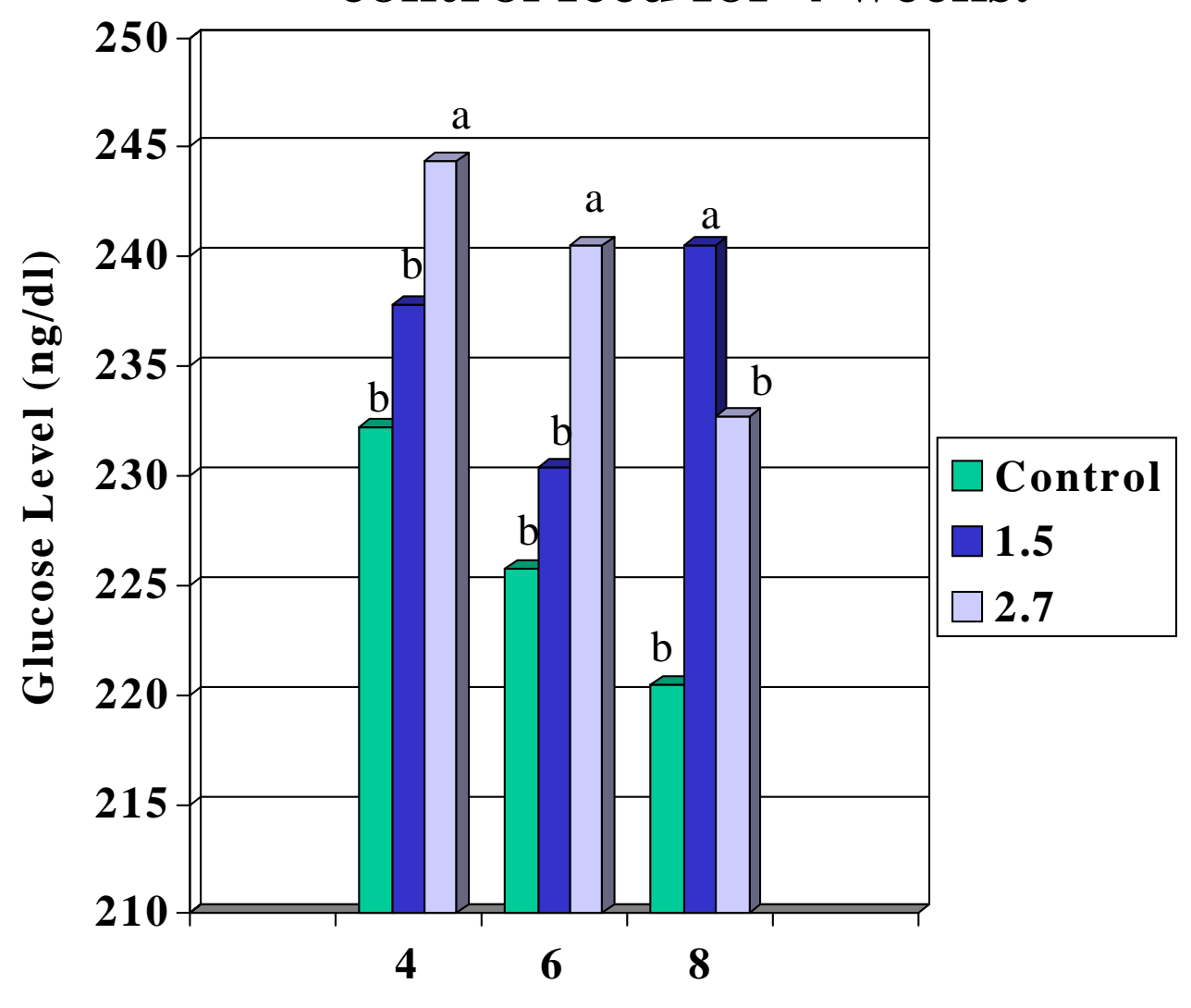

Weeks of age

a-c least square means for each week with common superscripts do not differ significantly $(\mathrm{p}<.01)$ 
Figure 21. Average plasma glucose levels of broilers fed calcium propionate at $1.5 \%$ and $2.7 \%$ for 6 weeks and finished on control feed for 2 weeks.

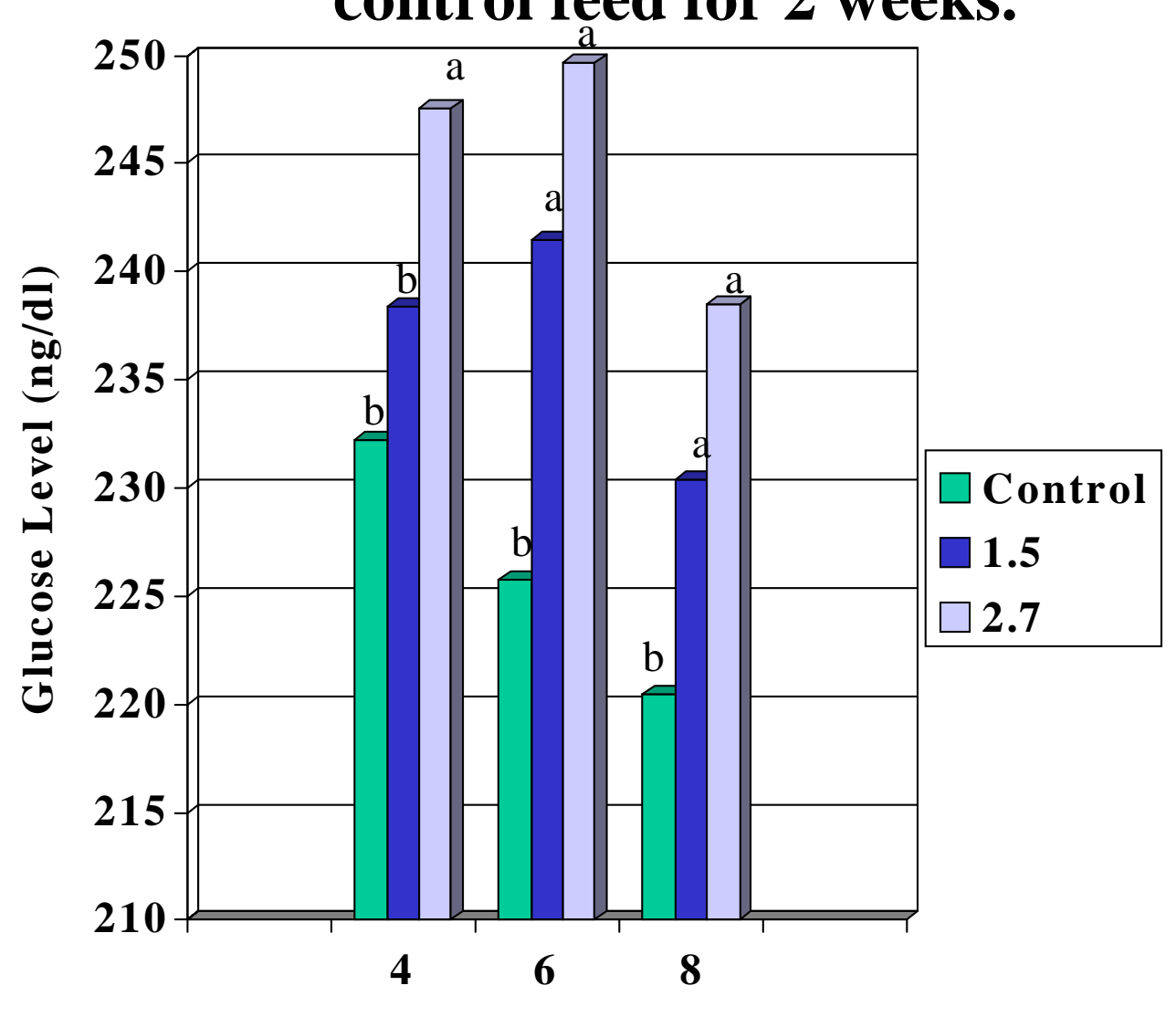

Weeks of age

a-c least square means for each week with common superscripts do not differ significantly $(\mathrm{p}<.01)$ 


\section{Figure 22. Average plasma glucose levels of broilers fed calcium propionate at $1.5 \%$ and $2.7 \%$ for 8 weeks.}

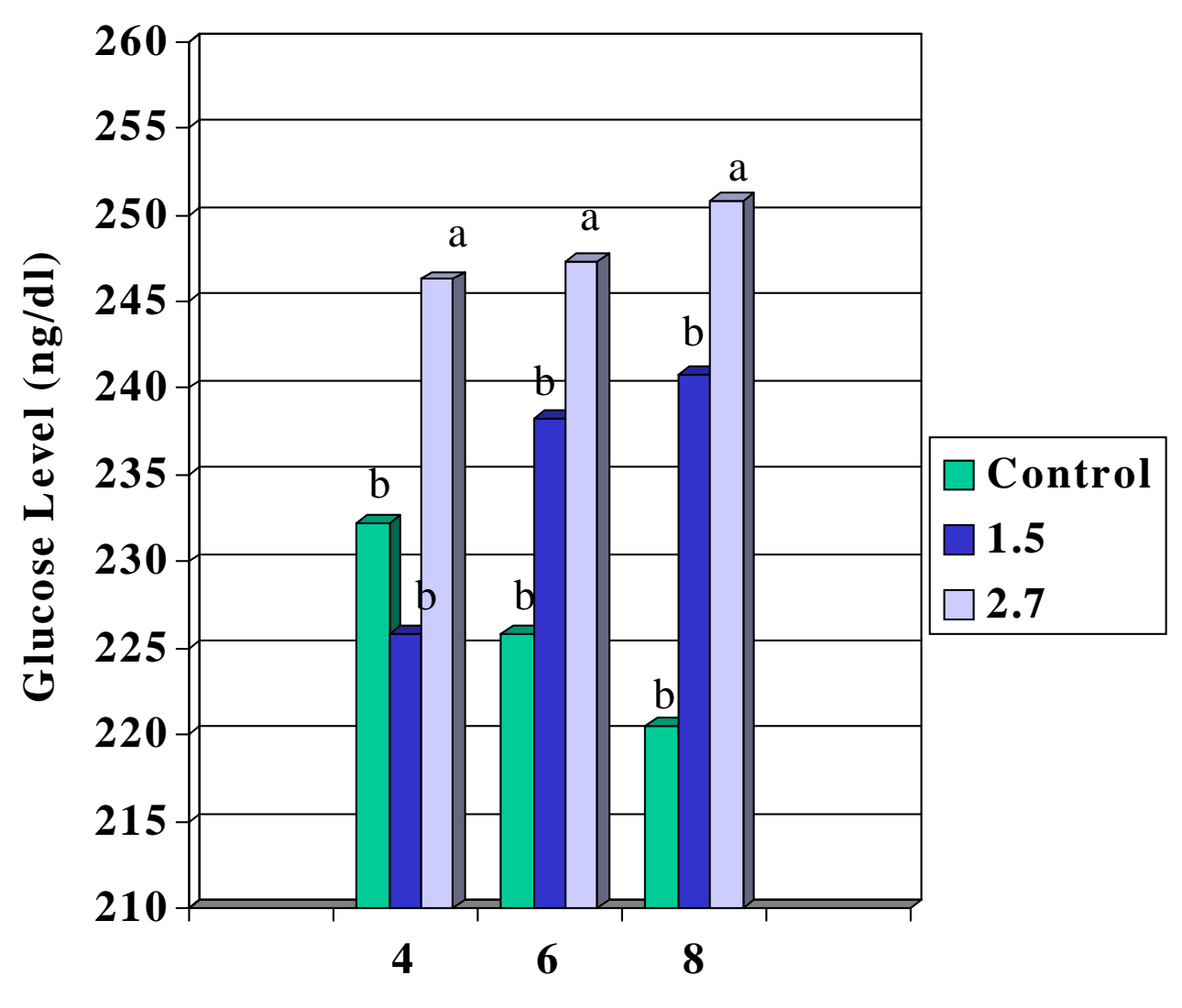

Weeks of age

a-c least square means for each week with common superscripts do not differ significantly $(\mathrm{p}<.01)$ 


\section{Chapter 5. Discussion}

Improved feed efficiency and reduced body fat deposition are two of the major challenges that face the broiler researcher in meeting the needs of the industry and consumer. Health conscious consumers are also interested in a product with a reduced fat content. In view of these concerns several nutritional and management methods have been proposed to reduce fat accumulation during the early growth period.

The difficulties of mechanical feed restriction to limit food intake are numerous. For example, an even feed distribution is not achieved across all birds, because some birds are more aggressive than others are and consume more feed. This makes a chemical feed restriction method much more attractive. Pinchasov (1993) and Cave (1984) supplemented diets with CaP for up to 10 weeks of age to reduce feed intake and body weights. These studies showed diets supplemented with calcium CaP caused broilers to voluntarily consume less feed and thus have lower body weights. The longer the broilers were fed CaP, the greater the effects on feed intake and body weight. The results of these studies are consistent with results of Pinchasov and Cave. The greater the duration of CaP feed, in the diet the lower the body weights of the treated animal. 
In agreement with previous studies the inclusion of CaP at a 1.5 or $2.7 \%$ level in the diets of broilers resulted in consistent changes in live body weight, carcass composition, plasma glucose and concentrations of plasma growth hormone. The average weights of broilers fed CaP were lower throughout the experiment (Figures 1 through 4). When CaP was removed from the diet and the broilers were fed a control diet, they gained weight but were never able to completely compensate from their original weight loss. Broilers fed CaP had lower weight gains, but gained more than control broilers after CaP was removed from the diet (Figures 5 through 8). The average feed intake of broilers fed CaP was less than the control broilers and when removed from the treatment and returned to a control diet feed consumption was increased. Feed efficiency was also improved for broilers on CaP during the first two weeks but after that time they had lower feed to gain ratios than control broilers. Live and carcass weights of 8 week old broilers slaughtered for carcass analysis showed that broilers receiving $1.5 \%$ weighed more than those fed $2.7 \%$ CaP diets (Figure 13) .

Percent carcass fat of 8 week old broilers compared to the controls were consistently lower when fed a 2.7\% diet, which correlated the measurements of live weight (Figures 1 through 4 and figure 10). The inclusion of CaP lowered body weight and 
decreased the ratio of fat to protein in the carcass. These studies are consistent with the results of Plavnik et al. $(1986,1988,1990)$ that reported that mechanical restriction of broilers from 7 to 14 days after hatch delayed the time to reach market weight but improved feed conversion and reduced abdominal fat content. In contrast, Denton (1995) did not find a reduction in abdominal fat in feed restricted broilers although compensatory growth occurred in treated birds and feed conversion was improved. The lack of agreement between the studies has been linked to the different genetic makeup of the broiler strains. The view that genetic composition interacts with the nutritive content of the diet to yield contradicting results is consistent with results from the present study. In a different strain of broilers, (Klandorf et al.,1995) the inclusion of 1.5\% CaP induced a greater magnitude of increase in plasma glucose as compared to the smaller increment generated by a higher (2.7\%) dose used in the present study. It is thus important to establish the sensitivity of each strain of broilers to the satiety effects of CaP.

Percent carcass protein was also higher in birds fed $1.5 \%$ and 2.7\% CaP throughout the trial (Figure 12). These data are consistent with the reduction in body fat in birds fed CaP. The inclusion of CaP lowered body weight and increased the ratio of protein to fat in the carcass. 
In agreement with previous studies, plasma concentrations of glucose were higher for broilers fed CaP than the control broilers throughout the trial (Figures 19 through 22). In the study of Klandorf et al. (1995) plasma concentrations of glucose were proportionately greater than the results obtained in the present study. In view of these results it may be that the magnitude of the response to $\mathrm{CaP}$ in broilers may be strain dependent. Glucose is not a satiety factor in birds and so the observed increase in its concentration is not believed to be directly due to feeding CaP but due to the increase in plasma concentrations of $\mathrm{GH}$ induced by CaP (Younken et al., 1994). However, even after the CaP was removed from the broiler diets, the plasma glucose levels remained proportionately higher than the concentrations observed in the control broilers. Plasma glucose levels were consistently higher throughout the trials in broilers fed a 2.7\% CaP ration than those fed a $1.5 \%$ CaP ration.

Plasma growth hormone levels followed a pattern similar to that observed in the concentrations of plasma glucose, at both 1.5 and 2.7\% CaP (Figures 15 through 18). Concentrations of plasma growth hormone were consistently higher in broilers receiving $2.7 \%$ CaP diets as compared to those receiving $1.5 \%$ diets. These results are consistent with those observed by Younken (1994), where elevated $\mathrm{GH}$ levels in broilers were associated with 
increased plasma glucose concentrations.

It is hypothesized that the dose-dependent increase in the concentration of growth hormone, in response to the inclusion of CaP in the diet, acts as a satiety factor to reduce feed intake. Younken et al. (1994) has previously demonstrated the satiety effect of $\mathrm{GH}$ in poultry. The observation that the satiety effects of CaP decreased with age is consistent with the age-related decline in GH during the trial period as well as the reduced increment in GH release that could be induced in the older chicks. This would help to explain the pronounced effect of CaP on reducing food consumption in the weeks immediately after hatch. The increases in concentrations of plasma glucose are suggested to be in response to the $\mathrm{GH}$ induced by CaP. The precise mechanism by which CaP induces $\mathrm{GH}$ release from the avian pituitary remains to be investigated. It would also be of interest to determine whether the mechanism of action of related compounds to CaP also induce an increase in circulating GH levels. The increase in the levels of glucose and growth hormone correlate with the CaP level in the feed, other compounds in the brain may also be affected and thus trigger the satiety mechanism. 


\section{Chapter 6. Conclusion}

The inclusion of calcium propionate in the diet of broilers depressed feed consumption and weight gains during each of the four measured weight periods. Removal of calcium propionate from the diet permitted compensatory gain but not to the weights of the controls.

The fat pad weights and carcass fat measurements as determined by proximate analysis were lower on treated broilers than on control broilers. This method of feed restriction via chemical inclusion can be a useful tool to alter levels of growth hormone and plasma glucose, resulting in favorable changes in body composition. A negative consequence would be the increased amount of time for CaP birds to reach normal market age for broilers in the U.S.

The inclusion of calcium propionate in the diets of broilers could be an effective means to alter the body composition of broilers to meet the demands of the increasingly health conscious consumer. Specific recommendations include the possibility of including calcium propionate in the diets of birds if customers are insistent on a lower fat product. However, industry looks at all costs very closely and calcium propionate inclusion is more costly than conventional rations and might be difficult to prove cost-effective. Also, growers for the industry have their pay 
based on feed conversion and weight gain. Although calcium propionate improves feed conversion it delays weight gain, and so it would be a challenge for industry to implement these changes without some resistance from the growers.

Future studies could look at increased calcium propionate amounts in rations for a shorter duration to observe what effects if any it would have on the broilers. Also, a comparison of chemical versus mechanical means of restrictions could be observed to see what would be most cost effective for industry to implement. Perhaps a trial using a cheap feed additive such as rice hulls in a comparison trial with calcium propionate could show some interesting results. 


\section{Literature Cited}

Auckland, J.N., 1972. Compensatory growth in turkeys: practical implications and limitations. World's Poult. Sci. J. 28:291-300.

Ballam, G.C., and B.E. March, 1979. Adipocyte size and number in mature broiler-type female chickens subjected to dietary

restriction during the growing period. Poultry Sci. 58:940-948.

Barnes, B. A., and B. F. Miller, 1981. Protein restriction and growth in roaster chicks. Poultry Science 60: 336-341.

Bartov, I., 1987. Effect of early nutrition on fattening and growth of broiler chicks at 7 weeks of age. Br. Poult. Sci. $28: 507-518$.

Beane, W. L., J. A. Cherry, and W. D. Weaver Jr., 1979. Intermittent light and restricted feeding of broiler chickens. Poultry Science 58: 567-571.

Beane, W.L., P.B. Siegel, and H.S. Siegel, 1962. The effect of light on body weight and feed conversion of broilers. Poultry Sci. 41:1350-1351.

Blundell, J.E.,1977. Is there a role for serotonin in feeding? Int. J. Obesity $1: 15-42$.

Buckland, R.B., D.E. Bernon, and A. Goldrosen, 1976. Effect of four lighting regimens on broiler performance, leg abnormalities, and plasma corticoid levels. Poultry Sci. 55:1072-1076.

Buyse, J., and E. Decuypere, 1988. The influence of intermittent light on broiler performance and on patterns of food intake. Pages 133-134 in : Leanness in Domestic Birds. Genetics, Metabolic and Hormonal Aspects. B. Leclercq, and C.C. Whitehead, ed. Butterworths, London, UK.

Calvert, C.C., J.P. McMurtry, R.W. Rosebrough, and R.G. Campbell, 1987. Effect of energy level on the compensatory growth response of broilers following early feed restriction. Poultry sci. 66 (Suppl.) : 75 .

Cave, N. A. G., 1984. Effect of Dietary Propionic and Lactic Acids on Feed Intake by Chicks. Poultry Science 63: 131-134.

Cave, N. A. G., 1982. Effect of Dietary Short- and Medium-Chain Fatty Acids on Feed Intake by Chicks. Poultry Science 61: 11471153 . 
Cherry, J.A., P.B. Siegel, and W.L. Beane, 1978. Geneticnutritional relationships in growth and carcass characteristics of broiler chickens. Poultry Sci. 57:1482-1487.

Classen, H.L. and C. Riddell, 1989. Photoperiodic effects on performance and leg abnormalities in broiler chickens. Poultry Sci. 68:873-879.

Duncan, D.B., 1955. Multiple range and multiple F tests. Biometerics 11:1-42.

Fancher, B.I., and L.S. Jensen, 1988. Induction of voluntary feed intake restriction in broiler chicks by dietary glycolic acid supplementation. Poultry Sci. 67:1469-1482.

Fisher, C., 1984. Fat deposition in broilers. Pages 437-470 in: Fats in Animal Nutrition. J. Wiseman, ed. Proc. Easter School in Agricultural Science, University of Nottingham (37 $7^{\text {th }}$, Butterworth, London, UK.

Graham, N. M., and T. W. Searle, 1975. Studies of weaned sheep during and after a period of weight stasis. I. Energy and nitrogen utilization. Austr. J. Agric. Res. 26: 343-353.

Griffiths, L., S. Leeson, and J.D. Summers, 1977. Fat deposition in broilers: effect of dietary energy to protein balance, and early life caloric restriction on productive performance and abdominal fat pad size. Poultry Sci. 56:638-646.

Huff, W.E., J.M. Balog, G.R. Bayyari, and N.C. Rath, 1994. The effect of Mycocurb, propionic acid, and calcium propionate on the intestinal strength of broiler chickens. Poultry Sci. 73:13521356 .

Hume, M.E., D.E. Corrier, G.W. Ivie, and J.R. Deloach, 1993. Metabolism of Propionic Acid in Broiler Chicks. Poultry Sci. $72: 786-793$.

Jurgens, M. H., 1988. Evaluating Feedstuffs for Farm Livestock. p. 51. Animal Feeding and Nutrition. Sixth Edition. Kendall/Hunt, Dubuque, Iowa.

Lacy, M.P., H.P. Van Krey, D.M. Denbow, P.B. Siegel, and J.A. Cherry, 1982. Amino acid regulation of food intake in domestic fowl. Nutr. Behav. 1:65-74.

Leenstra, F.R., 1986. Effect of age, sex, genotype and environment on fat deposition in broiler chickens-a review. World's Poult. Sci. J. 42:12-25. 
Mallard, J., and M. Douaire, 1988. Strategies of selection for leanness in meat production. p.3-23. Leanness in Domestic Birds. Genetics, Metabolic and Hormonal Aspects. B. Leclercq and C. C. Whitehead, ed. Butterworths, London, UK.

Marks, H.L., 1979. Growth rate and feed intake of selected and non-selected broilers. Growth 43:80-90.

Masic, B., D.G.M. Wodd-Gush, I.J.H. Duncan, C. McCorquodale, and C.J. Savory, 1974. A comparison of the feeding behavior of young broiler and layer males. Br. Poult. Sci. 15:499-505.

McMurtry, J. P., R. W. Rosebrough, I. Plavnik, and A. L. Cartwright, 1988. Influence of early plane of nutrition on enzyme systems and subsequent tissue deposition. p. 329-341. Biomechanisms Regulating Growth and Development. G. L. Steffens and T. S. Rumsey, ed. Beltsville Symposia on Agricultural Research (12), Klumer Academic Publishers, Dordrecht, The Netherlands.

Mollison, B., w. Guenter, and B.R. Boycott, 1984. Abdominal fat deposition and sudden death syndrome in broilers: the effect of restricted intake, early life caloric (fat) restriction, and calorie:protein ratio. Poultry Sci. 63:1190-1200.

Moore, C.H., 1957. The effect of light on growth of broiler chickens. Poultry Sci. 36:1142-1143.

Moran, E. T., Jr., 1979. Carcass quality changes with the broiler chickens after dietary protein restriction during the growing phase and finishing period compensatory growth. Poultry Science 58: 1257-1270.

Mosier, H. D. Jr., 1986. The control of catch-up growth. Acta Endocrinol. 113: 1-7.

National Research Council, 1984. Nutrient requirements of poultry. $8^{\text {th }}$ rev. ed. National Academy Press, Washington, DC.

North, M. O., and D. D. Bell, 1990. Broiler, Roaster, and Capon Management. p. 458. Commercial Chicken Production Manual. Fourth Edition. Van Nostrand, New York.

O'Donovan, P. B., 1984. Compensatory gain in cattle and sheep. Nutr. Abstr. Rev. (Series B) 54: 389-410.

Ononiwu, J.C., R.G. Thomson, H.C. Carlson, and R.J. Julian, 1979. Studies on the effect of lighting on "sudden death syndrome" in broiler chickens. Can. Vet. J. 20:74-77.

Pasternak, H., and B. A. Shalev, 1983. Genetic-economic Evaluations of Traits in a Broiler Enterprise: Reduction of Food Intake Due to Increased Growth Rate. Br. Poult. Sci. 24: 531- 
Pinchasov, Y., and L.S. Jensen, 1989. Comparison of physical and chemical means of feed restriction in broiler chicks. Poultry Sci. $68: 61-69$.

Pinchasov, Y., D. Galili, N. Yonash, and H. Klandorf, 1993. Effect of Feed Restriction Using Self-Restricting Diets on Subsequent Performance of Broiler Breeder Females. Poultry Science 72: 613-619.

Pitts, G. C., 1986. Cellular aspects of growth and catch-up growth in the rat: a reevaluation. Growth 50: 419-436.

Plavnik, I., and S. Hurwitz, 1985. The Performance of Broiler Chicks During and Following a Severe Feed Restriction at an Early Age. Poultry Science 64: 348-355.

Plavnik, I., J. P. McMurtry, and R. W. Rosebrough, 1986. Effects of Early Feed Restriction in Broilers. I. Growth performance and Carcass Composition. Growth 50: 68-76.

Plavnik, I. and S. Hurwitz, 1990. Performance of broiler chickens and turkey poults subjected to feed restriction or to feeding low-protein or low-sodium diets at an early age. Poultry Sci. 69:945-952.

Plavnik, I., and S. Hurwitz, 1991. Response of Broiler Chickens and Turkey Poults to Feed Restriction of Varied Severity During Early Life. Br. Poul. Sci 32: 343-352.

Polin, D. and J.H. Wolford, 1973. Factors influencing food intake and caloric balance in chickens. Fed. Proc. 32:1720-1726.

Robinson, F.E., H.L. Classen, J.A. Hanson, and D.K. Onderka, 1992. Growth performance, feed efficiency and the incidence of skeletal and metabolic disease in full-fed and feed restricted broiler and roaster chickens. J. Appl. Poultry res. 1:33-41.

SAS Institute, 1988. SAS/STAT User's Guide: 1988 Edition. SAS Institute, Inc., Cary, NC.

Sibbald, I. R. and A. Fortin, 1982. Preparation of Dry Homogenates from Whole and Eviscerated Chickens. Poultry Science 61 : 589-590.

Spencer, J. V., W. A. Becker, J. A. Verstrate, and L. W. Mirosh, 1978. Relationship of Carcass Fat to Abdominal Fat and Specific Gravity in Broiler Chickens. Poultry Science 57: 1164.

Summers, J.D., D. Spratt, and J.L. Atkinson, 1990. Restricted feeding and compensatory growth for broilers. Poultry Sci. 69 :1855-1861. 
Vohra, P., W. O. Wilson, and T. D. Siopes, 1975. Meeting the energy needs of poultry. Proc. Nutr. Soc. 34: 13-18.

Wilson, P. N., and Osbourn, 1960. Compensatory growth after under nutrition in mammals and birds. Biol. Rev. 35: 324-363.

Wilson, J.L., W.D. Weaver, Jr., W.L. Beane, and J.A. Cherry, 1984. Effect of lighting and feeding space on leg abnormalities in broilers. Poultry Sci. 63:565-567.

Winick, M., and A. Noble, 1966. Cellular response in rats during malnutrition at various ages. J. Nutr. 89: 300-306.

Wolynetz, M. S., and I. R. Sibbald, 1986. Prediction of Major Body Components of Broiler Chicks. Poultry Science 65: 21732185 .

Yeh, Y. Y., and G. A. Leveille, 1970. Hepatic fatty acid synthesis and plasma free fatty acid levels in chicks subjected to short periods of food restriction and refeeding. J. Nutr. $100: 1389-1398$.

Younken, R. V. , 1994. Proposed Mechanisms for the Regulation of Growth Hormone Action in Poultry: Metabolic Effects. Symposium: Poultry Nutrition Conference.

Younken, R. V., T. L. Cravener, L. A. Cogburn, M. G. Mast, and R. H. Wellenreiter, 1988. Effect of Pattern of Administration on the Response to Exogenous Pituitary-Derived Chicken Growth Hormone by Broiler-Strain Pullets. Gen. and Comp. Endocrinology $71: 268-283$.

Yu, M. W., and F. E. Robinson, 1992. The Application of ShortTerm Feed Restriction to Broiler Chicken Production: A Review. J. Appl. Poultry Res. 1: 147-153.

Yu, M. W., F. E. Robinson, M. T. Clandinin, and L. Bodnar, 1990. Growth and Body Composition of Broiler Chickens in Response to Different Regimens of Feed Restriction. Poultry Science 69: 2074-2081.

Zubair, A. K. and S. Leeson, 1994. Effect of Varying Period of Early Nutrient Restriction on Growth Compensation and Carcass Characteristics of Male Broilers. Poultry Science 73: 129-136. 
APPENDIX 1. TABLES 1-4

Table 1: Average Weight of Broilers Fed Calcium Propionate For 2 Weeks and Finished On Control Feed For 6 Weeks

\begin{tabular}{|c|c|c|c|c|c|c|}
\hline Weeks & Control & SEM & $1.5 \%$ & SEM & $2.7 \%$ & SEM \\
\hline 2 & 0.342 & 0.0048 & 0.279 & 0.0048 & 0.215 & 0.0048 \\
\hline 4 & 1.030 & 0.0153 & 0.981 & 0.0310 & 0.817 & 0.0310 \\
6 & 2.070 & 0.0190 & 1.990 & 0.0380 & 1.720 & 0.0380 \\
\hline 8 & 2.950 & 0.0291 & 2.890 & 0.0582 & 2.610 & 0.0582 \\
\hline
\end{tabular}

Table 2: Average Weight of Broilers Fed Calcium Propionate For 4 Weeks and Finished On Control Feed For 4 Weeks

\begin{tabular}{|c|c|c|c|c|c|c|}
\hline Weeks & Control & SEM & $1.5 \%$ & SEM & $2.7 \%$ & SEM \\
\hline 2 & 0.342 & 0.0048 & 0.279 & 0.0048 & 0.215 & 0.0048 \\
\hline 4 & 1.030 & 0.0153 & 0.848 & 0.0177 & 0.667 & 0.0177 \\
\hline 6 & 2.070 & 0.0190 & 1.950 & 0.0380 & 1.640 & 0.0380 \\
\hline 8 & 2.950 & 0.0291 & 2.870 & 0.0582 & 2.640 & 0.0582 \\
\hline
\end{tabular}

Table 3: Average Weight of Broilers Fed Calcium Propionate For 6 Weeks and Finished On Control Feed For 2 Weeks

\begin{tabular}{|c|c|c|c|c|c|c|}
\hline Weeks & Control & SEM & $1.5 \%$ & SEM & $2.7 \%$ & SEM \\
\hline 2 & $0.342 \mathrm{~kg}$ & 0.0048 & $0.279 \mathrm{~kg}$ & 0.0048 & $0.215 \mathrm{~kg}$ & 0.0048 \\
\hline 4 & $1.030 \mathrm{~kg}$ & 0.0153 & $0.848 \mathrm{~kg}$ & 0.0177 & $0.667 \mathrm{~kg}$ & 0.0177 \\
\hline 6 & $2.070 \mathrm{~kg}$ & 0.0190 & $1.790 \mathrm{~kg}$ & 0.0267 & $1.480 \mathrm{~kg}$ & 0.0267 \\
\hline 8 & $2.950 \mathrm{~kg}$ & 0.0291 & $2.830 \mathrm{~kg}$ & 0.0582 & $2.580 \mathrm{~kg}$ & 0.0582 \\
\hline
\end{tabular}

Table 4: Average Weight of Broilers Fed Calcium Propionate For 8 Weeks

\begin{tabular}{|c|c|c|c|c|c|c|}
\hline Weeks & Control & SEM & $1.5 \%$ & SEM & $2.7 \%$ & SEM \\
\hline 2 & $0.342 \mathrm{~kg}$ & 0.0048 & $0.279 \mathrm{~kg}$ & 0.0048 & $0.215 \mathrm{~kg}$ & 0.0048 \\
\hline 4 & $1.030 \mathrm{~kg}$ & 0.0153 & $0.848 \mathrm{~kg}$ & 0.0177 & $0.667 \mathrm{~kg}$ & 0.0177 \\
\hline 6 & $2.070 \mathrm{~kg}$ & 0.0190 & $1.790 \mathrm{~kg}$ & 0.0267 & $1.480 \mathrm{~kg}$ & 0.0267 \\
\hline 8 & $2.950 \mathrm{~kg}$ & 0.0291 & $2.670 \mathrm{~kg}$ & 0.0582 & $2.240 \mathrm{~kg}$ & 0.0582 \\
\hline
\end{tabular}


APPENDIX 1. TABLES 5-8

Table 5: Weight Gain of Broilers Fed Calcium Propionate For 2 Weeks and Finished On Control Feed For 6 Weeks

\begin{tabular}{|c|c|c|c|c|c|c|}
\hline Weeks & Control & SEM & $1.5 \%$ & SEM & $2.7 \%$ & SEM \\
\hline 2 & $0.328 \mathrm{~kg}$ & 0.0086 & $0.237 \mathrm{~kg}$ & 0.0086 & $0.168 \mathrm{~kg}$ & 0.0086 \\
\hline 4 & $0.745 \mathrm{~kg}$ & 0.0252 & $0.783 \mathrm{~kg}$ & 0.0504 & $0.648 \mathrm{~kg}$ & 0.0504 \\
\hline 6 & $0.954 \mathrm{~kg}$ & 0.0273 & $1.010 \mathrm{~kg}$ & 0.0547 & $0.956 \mathrm{~kg}$ & 0.0547 \\
\hline 8 & $0.862 \mathrm{~kg}$ & 0.0307 & $0.789 \mathrm{~kg}$ & 0.0615 & $0.849 \mathrm{~kg}$ & 0.0615 \\
\hline
\end{tabular}

Table 6: Weight Gain of Broilers Fed Calcium Propionate For 4 Weeks and Finished On Control Feed For 4 Weeks

\begin{tabular}{|c|c|c|c|c|c|c|}
\hline Weeks & Control & SEM & $1.5 \%$ & SEM & $2.7 \%$ & SEM \\
\hline 2 & $0.328 \mathrm{~kg}$ & 0.0086 & $0.237 \mathrm{~kg}$ & 0.0086 & $0.168 \mathrm{~kg}$ & 0.0086 \\
\hline 4 & $0.745 \mathrm{~kg}$ & 0.0252 & $0.581 \mathrm{~kg}$ & 0.0291 & $0.437 \mathrm{~kg}$ & 0.0291 \\
\hline 6 & $0.954 \mathrm{~kg}$ & 0.0273 & $1.070 \mathrm{~kg}$ & 0.0547 & $0.925 \mathrm{~kg}$ & 0.0547 \\
\hline 8 & $0.862 \mathrm{~kg}$ & 0.0307 & $0.837 \mathrm{~kg}$ & 0.0615 & $0.908 \mathrm{~kg}$ & 0.0615 \\
\hline
\end{tabular}

Table 7: Weight Gain of Broilers Fed Calcium Propionate For 6 Weeks and Finished On Control Feed For 2 Weeks

\begin{tabular}{|c|c|c|c|c|c|c|}
\hline Weeks & Control & SEM & $1.5 \%$ & SEM & $2.7 \%$ & SEM \\
\hline 2 & $0.328 \mathrm{~kg}$ & 0.0086 & $0.237 \mathrm{~kg}$ & 0.0086 & $0.168 \mathrm{~kg}$ & 0.0086 \\
\hline 4 & $0.745 \mathrm{~kg}$ & 0.0252 & $0.581 \mathrm{~kg}$ & 0.0291 & $0.437 \mathrm{~kg}$ & 0.0291 \\
\hline 6 & $0.954 \mathrm{~kg}$ & 0.0273 & $0.932 \mathrm{~kg}$ & 0.0386 & $0.737 \mathrm{~kg}$ & 0.0386 \\
\hline 8 & $0.862 \mathrm{~kg}$ & 0.0307 & $0.976 \mathrm{~kg}$ & 0.0615 & $0.920 \mathrm{~kg}$ & 0.0615 \\
\hline
\end{tabular}

\begin{tabular}{|c|c|c|c|c|c|c|}
\hline \multicolumn{7}{|c|}{ Table 8: Weight Gain of Broilers Fed Calcium Propionate For 8 Weeks } \\
\hline Weeks & Control & SEM & $1.5 \%$ & SEM & $2.7 \%$ & SEM \\
\hline 2 & $0.328 \mathrm{~kg}$ & 0.0086 & $0.237 \mathrm{~kg}$ & 0.0086 & $0.168 \mathrm{~kg}$ & 0.0086 \\
\hline 4 & $0.745 \mathrm{~kg}$ & 0.0252 & $0.581 \mathrm{~kg}$ & 0.0291 & $0.437 \mathrm{~kg}$ & 0.0291 \\
\hline 6 & $0.954 \mathrm{~kg}$ & 0.0273 & $0.932 \mathrm{~kg}$ & 0.0386 & $0.737 \mathrm{~kg}$ & 0.0386 \\
\hline 8 & $0.862 \mathrm{~kg}$ & 0.0307 & $0.790 \mathrm{~kg}$ & 0.0615 & $0.857 \mathrm{~kg}$ & 0.0615 \\
\hline
\end{tabular}


APPENDIX 1. TABLES 9-12

Table 9: Average 8 Week Feed to Gain Ratio of Broilers Fed Calcium

Propionate at $1.5 \%$ and $2.7 \%$ and Finished On Control Feed

\begin{tabular}{|c|c|c|c|c|c|c|}
\hline Weeks & Control & SEM & $1.5 \%$ & SEM & $2.7 \%$ & SEM \\
\hline 2 & $2.08 \mathrm{~kg}$ & 0.0293 & $2.04 \mathrm{~kg}$ & 0.0478 & $2.07 \mathrm{~kg}$ & 0.0478 \\
\hline 4 & $2.08 \mathrm{~kg}$ & 0.0293 & $1.96 \mathrm{~kg}$ & 0.0478 & $1.87 \mathrm{~kg}$ & 0.0478 \\
\hline 6 & $2.08 \mathrm{~kg}$ & 0.0293 & $1.93 \mathrm{~kg}$ & 0.0478 & $1.85 \mathrm{~kg}$ & 0.0478 \\
\hline 8 & $2.08 \mathrm{~kg}$ & 0.0293 & $1.87 \mathrm{~kg}$ & 0.0478 & $1.79 \mathrm{~kg}$ & 0.0478 \\
\hline
\end{tabular}

\begin{tabular}{|c|c|c|c|c|c|c|}
\hline \multicolumn{6}{|c|}{$\begin{array}{c}\text { Table 10: Percent Carcass Fat of Eviscerated } 8 \text { Week Old Broilers Fed } \\
\text { Calcium Propionate at 1.5\% and 2.7\% and Finished On Control Feed }\end{array}$} \\
\hline Weeks & Control & SEM & $1.5 \%$ & SEM & $2.7 \%$ & SEM \\
\hline 2 & 13.45 & 0.6245 & 12.77 & 0.7211 & 12.99 & 0.7211 \\
\hline 4 & 13.45 & 0.6245 & 14.00 & 0.7211 & 12.37 & 0.7211 \\
\hline 6 & 13.45 & 0.6245 & 11.98 & 0.7211 & 9.50 & 0.7211 \\
\hline 8 & 13.45 & 0.6245 & 11.19 & 0.7211 & 9.50 & 0.7211 \\
\hline
\end{tabular}

\begin{tabular}{|c|c|c|c|c|c|c|}
\hline \multicolumn{6}{|c|}{ Table 11: Fat Pad Weight of Eviscerated 8 Week Old Broilers Fed } \\
Calcium Propionate at $1.5 \%$ and 2.7\% and Finished On Control Feed \\
\hline Weeks & Control & SEM & $1.5 \%$ & SEM & $2.7 \%$ & SEM \\
\hline 2 & $37.09 \mathrm{~g}$ & 4.175 & $35.73 \mathrm{~g}$ & 4.8211 & $33.55 \mathrm{~g}$ & 4.8211 \\
\hline 4 & $37.09 \mathrm{~g}$ & 4.175 & $36.71 \mathrm{~g}$ & 4.8211 & $26.47 \mathrm{~g}$ & 4.8211 \\
\hline 6 & $37.09 \mathrm{~g}$ & 4.175 & $40.75 \mathrm{~g}$ & 4.8211 & $21.99 \mathrm{~g}$ & 4.8211 \\
\hline 8 & $37.09 \mathrm{~g}$ & 4.175 & $36.57 \mathrm{~g}$ & 4.8211 & $24.36 \mathrm{~g}$ & 4.8211 \\
\hline
\end{tabular}

\begin{tabular}{|c|c|c|c|c|c|c|}
\hline \multicolumn{6}{|c|}{ Table 12: Percent Protein of Eviscerated 8 Week Old Broilers Fed } \\
Calcium Propionate at 1.5\% and 2.7\% and Finished On Control Feed \\
\hline Weeks & Control & SEM & $1.5 \%$ & SEM & $2.7 \%$ & SEM \\
\hline 2 & 18.32 & 0.1707 & 19.13 & 0.1971 & 18.81 & 0.1971 \\
\hline 4 & 18.32 & 0.1707 & 18.69 & 0.1971 & 18.93 & 0.1971 \\
\hline 6 & 18.32 & 0.1707 & 18.73 & 0.1971 & 18.53 & 0.1971 \\
\hline 8 & 18.32 & 0.1707 & 18.90 & 0.1971 & 19.02 & 0.1971 \\
\hline
\end{tabular}


Table 13: Live Weight of 8 Week Old Broilers

\begin{tabular}{|c|c|c|c|c|c|c|}
\hline Weeks & Control & SEM & $1.5 \%$ & SEM & $2.7 \%$ & SEM \\
\hline 2 & $2.89 \mathrm{~kg}$ & 0.0895 & $2.87 \mathrm{~kg}$ & 0.1033 & $2.64 \mathrm{~kg}$ & 0.1033 \\
\hline 4 & $2.89 \mathrm{~kg}$ & 0.0895 & $2.77 \mathrm{~kg}$ & 0.1033 & $2.53 \mathrm{~kg}$ & 0.1033 \\
\hline 6 & $2.89 \mathrm{~kg}$ & 0.0895 & $2.79 \mathrm{~kg}$ & 0.1033 & $2.16 \mathrm{~kg}$ & 0.1033 \\
\hline 8 & $2.89 \mathrm{~kg}$ & 0.0895 & $2.58 \mathrm{~kg}$ & 0.1033 & $2.36 \mathrm{~kg}$ & 0.1033 \\
\hline
\end{tabular}

\begin{tabular}{|c|c|c|c|c|c|c|}
\hline \multicolumn{7}{|c|}{ Table 14: Carcass Weight of 8 Week Old Broilers } \\
\hline Weeks & Control & SEM & $1.5 \%$ & SEM & $2.7 \%$ & SEM \\
\hline 2 & $2.00 \mathrm{~kg}$ & 0.0669 & $2.04 \mathrm{~kg}$ & 0.0773 & $1.85 \mathrm{~kg}$ & 0.0773 \\
\hline 4 & $2.00 \mathrm{~kg}$ & 0.0669 & $1.90 \mathrm{~kg}$ & 0.0773 & $1.73 \mathrm{~kg}$ & 0.0773 \\
\hline 6 & $2.00 \mathrm{~kg}$ & 0.0669 & $1.89 \mathrm{~kg}$ & 0.0773 & $1.42 \mathrm{~kg}$ & 0.0773 \\
\hline 8 & $2.00 \mathrm{~kg}$ & 0.0669 & $1.76 \mathrm{~kg}$ & 0.0773 & $1.60 \mathrm{~kg}$ & 0.0773 \\
\hline
\end{tabular}

Table 15: Plasma Growth Hormone Level of Broilers Fed Calcium Propionate For 2 Weeks and Finished On Control Feed For 6 Weeks

\begin{tabular}{|c|c|c|c|c|c|c|}
\hline Weeks & Control & SEM & $1.5 \%$ & SEM & $2.7 \%$ & SEM \\
\hline 4 & 43.00 & 8.293 & 39.00 & 16.585 & 51.00 & 16.585 \\
\hline 6 & 26.21 & 6.339 & 28.60 & 12.678 & 32.32 & 12.678 \\
\hline 8 & 21.13 & 3.122 & 24.25 & 6.244 & 28.50 & 6.244 \\
\hline
\end{tabular}

Table 16: Plasma Growth Hormone Level of Broilers Fed Calcium Propionate For 4 Weeks and Finished On Control Feed For 4 Weeks

\begin{tabular}{|c|c|c|c|c|c|c|}
\hline Weeks & Control & SEM & $1.5 \%$ & SEM & $2.7 \%$ & SEM \\
\hline 4 & 43.00 & 8.293 & 49.27 & 16.585 & 57.54 & 16.585 \\
\hline 6 & 26.21 & 6.339 & 30.61 & 12.678 & 41.20 & 12.678 \\
\hline 8 & 21.13 & 3.122 & 26.72 & 6.244 & 32.78 & 6.244 \\
\hline
\end{tabular}


Table 17: Plasma Growth Hormone Level of Broilers Fed Calcium Propionate For 6 Weeks and Finished On Control Feed For 2 Weeks

\begin{tabular}{|c|c|c|c|c|c|c|}
\hline Weeks & Control & SEM & $1.5 \%$ & SEM & $2.7 \%$ & SEM \\
\hline 4 & 43.00 & 8.293 & 52.98 & 16.585 & 60.21 & 16.585 \\
\hline 6 & 26.21 & 6.339 & 33.12 & 12.678 & 39.24 & 12.678 \\
\hline 8 & 21.13 & 3.122 & 30.13 & 6.244 & 35.26 & 6.244 \\
\hline
\end{tabular}

Table 18: Plasma Growth Hormone Level of Broilers Fed Calcium Propionate For 8 Weeks

\begin{tabular}{|c|c|c|c|c|c|c|}
\hline Weeks & Control & SEM & $1.5 \%$ & SEM & $2.7 \%$ & SEM \\
\hline 4 & 43.00 & 8.293 & 50.35 & 16.585 & 59.65 & 16.585 \\
\hline 6 & 26.21 & 6.339 & 34.68 & 12.678 & 41.29 & 12.678 \\
\hline 8 & 21.13 & 3.122 & 32.53 & 6.244 & 38.79 & 6.244 \\
\hline
\end{tabular}

Table 19: Plasma Glucose Level of Broilers Fed Calcium Propionate For 2 Weeks and Finished On Control Feed For 6 Weeks

\begin{tabular}{|c|c|c|c|c|c|c|}
\hline Weeks & Control & SEM & $1.5 \%$ & SEM & $2.7 \%$ & SEM \\
\hline 4 & 232.25 & 3.893 & 235.75 & 7.786 & 242.35 & 3.030 \\
\hline 6 & 225.80 & 4.880 & 235.93 & 9.760 & 238.85 & 6.060 \\
\hline 8 & 220.50 & 3.030 & 224.24 & 6.060 & 226.24 & 6.060 \\
\hline
\end{tabular}

Table 20: Plasma Glucose Level of Broilers Fed Calcium Propionate For 4 Weeks and Finished On Control Feed For 4 Weeks

\begin{tabular}{|c|c|c|c|c|c|c|}
\hline Weeks & Control & SEM & $1.5 \%$ & SEM & $2.7 \%$ & SEM \\
\hline 4 & 232.25 & 3.893 & 237.85 & 7.786 & 244.35 & 7.786 \\
\hline 6 & 225.80 & 4.880 & 230.38 & 9.760 & 240.50 & 9.760 \\
\hline 8 & 220.50 & 3.030 & 225.25 & 6.060 & 232.71 & 6.060 \\
\hline
\end{tabular}


APPENDIX 1. TABLES 21-22

\begin{tabular}{|c|c|c|c|c|c|c|}
\hline \multicolumn{7}{|c|}{ Table 21: Plasma Glucose Level of Broilers Fed Calcium Propionate For } \\
6 Weeks and Finished On Control Feed For 2 Weeks \\
\hline Weeks & Control & SEM & $1.5 \%$ & SEM & $2.7 \%$ & SEM \\
\hline 4 & 232.25 & 3.893 & 238.37 & 7.786 & 247.51 & 7.786 \\
\hline 6 & 225.80 & 4.880 & 241.50 & 9.760 & 249.70 & 9.760 \\
\hline 8 & 220.50 & 3.030 & 230.38 & 6.060 & 238.50 & 6.060 \\
\hline
\end{tabular}

\begin{tabular}{|c|c|c|c|c|c|c|}
\hline \multicolumn{7}{|c|}{ Table 22: Plasma Glucose Level of Broilers Fed Calcium Propionate For } \\
\hline Weeks & Control & SEM & $1.5 \%$ & SEM & $2.7 \%$ & SEM \\
\hline 4 & 232.25 & 3.893 & 237.15 & 7.786 & 246.27 & 7.786 \\
\hline 6 & 225.80 & 4.880 & 238.24 & 9.760 & 247.35 & 9.760 \\
\hline 8 & 220.50 & 3.030 & 240.75 & 6.060 & 250.75 & 6.060 \\
\hline
\end{tabular}


Name :

Birthplace:

Date of Birth:

Parents :

Wife:

Education:

Degrees Received:

Employment :
Robert Eric Jones

Morgantown, WV

July 31, 1970

William T. Jones

Joanna Sue Jones

Siobhan Ann Jones

Morgantown High School

1985-1988

West Virginia University

1988-1992

Bachelor of Science in Animal and Veterinary Sciences, West Virginia University 1992

Case Farms of Ohio

Chicken Hatchery Manager

1995-1997

Rocco, Inc.

Chicken Hatchery Manager 